\title{
LEGITIMIDAD DE LOS ESTADOS DE EXCEPCION, A LA LUZ DE LOS INSTRUMENTOS DE DERECHOS HUMANOS

\section{Daniel O'Donnell}

Este trabajo trata de las limitaciones que el Gob erno está autorizado legalmente a hacer en relación a la vigencia de los derechos humanos y constitucionales dentro de los estados de excepción y, en concreto, trata los casos de guerra, amenazas in. ternas y el principio de estricta necesidad.

En cada uno de ellos, el autor discute detalladamente la casuistica y los términos posibles de definición, desarrollando extensas explicaciones sobre la jurisprudencia europea, del Comité de Derechos Humanos de la Organización de las Naciones Unidas y de la Comisión Interamericana.

Mención especial cabe, al caso Lawless, al caso de Grecia y al de Irlanda versus el Reino Unido de los organismos europeos; y al Grupo de Trabajo Ad Hoc sobre Chile del sistema de las Naciones Unidas.

\section{INTRODUCCION}

El derecho internacional de los derechos humanos y en particular el derecho positivo, si bien reconoce el derecho del Estado de suspender el cumplimiento de determinados deberes impuesto por el derecho internacional en esa materia también condiciona tal derecho al cumplimiento de una importante serie de requisitos. Entre ellos se destacan la tipificación de las circunstancias que justifican la suspensión (Articulo 4.1 del Pacto Internacional Sobre Derechos Civiles y Politicos Artículo 27.1. de la Convención

(*) Versión revisada de un trabajo presentado a la segunda reunión regional sobre "La Protección constitucional de los derechos humanos en América Latina, a la luz de los instrumentos internacionales de derechos humanos". 
Americana de Derechos Humanos); el principio de necesidad, que unos dividen en el principio de proporcionalidad y temporalidad (Artículo 4.1 y 27.1, respectivamente); el principio de nodiscriminación (Articulo 4.1 y 27.1, respectivamente); la clasificación de ciertos derechios como "no-suspendibles" (Artículo 4.2 y 27.2 , respectivamente) y en el sistema Americano, la extensión de la 'no-suspendibilidad' a las garantías judiciales necesarias para la efectiva protección de los derechos a los cuales se aplican la clas ficación (Artículo 27.2); el principio de la publicidad de medidas de suspensión (Artículo 4.1 y 4.2 del Pacto Internacional; Artículo 27.3 de la Convención Americana); la prohibición de emplear cualquier derecho reconocido por los instrumentos de derechos humanos para "destruir" o restringir indebidamente otro de los derechos reconocidos en ellos (Artículo 5.1 y 29.a, respectivamente); el principio según el cual cualquier limitación a un derecho humano debe ser consistente con la democracia (Artículo 29.2 de la Declaración Universal) y el principio de que la suspensión del cumplimiento de un instrumento de derechos humanos no debe afectar obligaciones en materia de derechos humanos procedientes de otras fuentes de derecho positivo o consuetudinario (Artículo 4.1 y 27.1, respectivamente). Cabe recordar que el reconocimiento de este derecho a la suspensión, con todas las condiciones que fijan su contenido, vino a sustituir la estrictísima (desde la perspectiva del Estado) regla tradicional del derecho de los tratados que legitima el no cumplimiento con deberes contraidos en instrumentos internacionales sólo cuando éste es literalmente imposible. (Artículo 61, Convenio de Viena Sobre el Derecho de los Tratados). Tal circunstancia histórica-jurídico subraya la imprescindible importancia de cada una de las restricciones al derecho a la suspensión, igual que la conveniencia, desde el punto de vista doctrinal por lo menos, de exigir el más estricto acatamiento de ellos cada vez que un Estado recurre a este derecho con la pretención de justificar el no respeto de los derechos humanos de sus ciudadanos.

El presente trabajo se limita a abarcar dos de esas limitaciones, la tipificación de las circunstancias que justifican la suspensión y el principio de estricta necesidad, y eso sólo parcialmente ya que, por razones fuera de nuestra voluntad, ha sido necesario prescindir del examen de las crisis económicas y catástrofes naturales como motivos de la suspensión. 


\section{PARTE I}

\section{LA GUERRA COMO MOTIVO DE LA SUSPENSION DE GARANTIAS}

La primera de las limitaciones que será examinada es la definición de las circunstancias que pueden justificar la declaración de una emergencia y la toma de medidas para la suspensión de las normas internacionales de derechos humanos. Son diferentes las definiciones de estas circunstancias contenidas en los dos tratados principales sobre derechos humanos en vigencia en las Américas, a saber el Pacto Internacional y la Convención Americana. Mientras que el Pacto Internacional se refiere a una "emergencia pública que amenaza la vida de la nación" la Convención utiliza el vocablo "la guerra, el peligro público u otra emergencia que amenaza la independencia o seguridad de un Estado Parte". La Convención Europea es parecida a la Americana al mencionar la guerra además de otras emergencias públicas, y semejante al Pacto Internacional en emplear las palabras "que amenaza la vida de la nación" en lugar de "que amenaza la independencia o seguridad de un Estado Parte".

Estas definiciones contienen tres elementos distintos pero interrelacionados: el tipo de situación que puede dar lugar al derecho a la suspensión, el grado de gravedad o inminencia que se requiere, y la identificación del bien jurídico amenazado. En otras palabras: qué clase de emergencia se contempla, qué gravedad debe tener, y qué es lo que debe estar en peligro.

Los comentaristas han identificado cuatro tipos de emergencias que pueden justificar la suspensión de normas de derechos humanos: la guerra u otra amenaza internacional de carácter militar. desórdenes internos o amenazas contra la seguridad nacional o el orden público, catástrofes naturales y emergencias económicas (ésta ampliada por algunos autores para incluir el subdesarrollo) (1). Consideramos en el presente capitulo el primero de ellos.

(1) Marks, Stephen, "La notion de Period d'exception en Matiere de Droits de J'Homme" en Les Dimensions Internationales des Droits de 1' Homme, UNESCO, Paris, 1978 y Questiaux, Nicole, Etude Sur les 


\section{1 ¿Es la Guerra Siempre Justificación de la Suspensión de Garantias?}

La primera interrogante que surge con respecto al uso del tërmino "guerra" en la Convención Americana es saber si la existencia de la guerra permite necesariamente soslayar obligaciones en materia de derechos humanos. A menudo se presume que la guerra constituye una amenaza real y presente a la vida de la nación o a la independencia y seguridad del Estado. Los comentaristas aún invocan la regla ejusden generis para enfatizar la gravedad y carácter excepcional requeridos por "otras" emergencias: para justificar la suspensión ellas deben ser "tan serias como la guerra" (2). Aunque este argumento tiene cabida frente a ciertos pretendidos abusos del derecho a la suspensión, técnicamente la guerra, igual que cualquier otra clase de emergencia, debe satisfacer todos los elementos del Articulo 27 (1) de la Convención. Así, Norris y Deiton comentan. "la mera existencia de una guerra declarada o ataque extranjero no seria suficiente para justificar la suspensión"; sólo sería suficiente "una guerra o ataque que representa un peligro real $e$ inminente a la independencia o seguridad del Estado" (3). De manera que, por ejemplo, en una guerra que ocurre en territorio extranjero, una guerra declarada pero en la cual no hay hostilidades actuales, o una guerra prolongada de guerrillas que tiene lugar en una remota y escasamente poblada parte del tarritorio nacional, es posible que no se justifique la suspensión de obligaciones referentes a los derechos humanos. EJ conflicto entre Argentina y el Reino Unido en 1982 por las Malvinas nos proporciona un ejemplo no sin una cierta ironia: durante el periodo en que las fuerzas argentinas ejercian control sobre las islas, el Gobierno de Argentina declaró que ellas eran la única parte del territorio nacional que no estaba sujeta al estado de sitio entonces vigente.

Consequences por los Droits del Honme del Développments Recents Concernant les Situations dites d'Etat de Siege ou Exceptions un Doc. ECN. 4/Sub2/1982/15 (1982).

(2) Infra, pág. 32.

(3) Norris, Robert y Desio Reiton, Paula.

The suspension of Guarantees: A Comparative Analysis of the Amrican Convention of Human Rights and the Constitutions of the States parties". American Univ. Law Review, vol. 30. No 1 (Fall 1980), pảg. 194. 


\section{2 ¿Qué Clase de Guerra Preveen los Pactos de Derechos Humanos?}

Es interesante notar al respecto que, como señala Martins, el decreto francés de 1791, fuente histórica directa del estado de sitio latinoamericano, establece que el estado de sitio se considera más grave que el estado de guerra. Sin embargo, precisamente porque el estado de sitio tenía consecuencias más amplias que el estado de guerra, y que se usaba contra el propio pueblo en tiempos de desórdenes civiles, desde el momento de la reforma napoleónica en 1815 la Constitución estipuló que si bien el estado de guerra podria ser declarado por el ejecutivo, sólo la legislatura, como representante del pueblo, podría imponer el estado de sitio (4).

La segunda pregunta que surge es ¿qué clase de guerra puede justificar la suspensión de las normas? Sobre esta cuestión Norris y Deiton opinan que "no hay por qué presumir que el significado de guerra en el Artículo 27 no es conforme con los conceptos tradicionales de la guerra en el derecho internacional", entonces ni la guerra civil ni "conflictos armados" de tipo no internacional están incluidos bajo el término "guerra" en aquel Artículo (5). Asi con el afán de construir tipologia restrictiva de guerra como motivo de la suspensión de garantias, se usa la definición clásica de la guerra como "una contención entre dos o más partes por medio de sus fuerzas armadas con el fin de vencer el uno al otro e imponer tales condiciones de paz como le plazcan al vencedor" (la misma definición c tada por el Sr. Süsterhenn en su opinión disidente en la decisión de la Comisión Europea de Derechos Humanos sobre el caso Lawless) (6).

Esta conclusión parece inconsecuente por varias razones. Primero, la interpretación parece bastante gratuita, puesto que los autores no la apoyan con ninguna referencia a los trabajos preparatorios ni a otra fuente autorizada de interpretación. Más importante, la distinción entre la guerra en el sentido clásico y la gue-

(4) Martins, Daniel Hugo, Estudio Preliminar del Estado de Sitio y la Protección de los Derechos Humanos en los Estados Americanos, Doc. OEA/ser. L/V/II 8 No 6 (1963).

(5) Norris y Desio Reitor (Supra nota 3) pág. 195.

(6) Ibid, pág. 194-5, Caso Lawless, C.E.D.H. Serie B., 1960-61, pág. 94. 
rra en el sentido más amplio es de poca relevancia en el contexto de la Convención. Parecía ser que cualquier guerra civil, insurrección o conflicto armado no internacional que amenace la independencia o seguridad del Estado const tuiria "un peligro público u otra emergencia", --y' por lo tanto justificará la suspensión, aunque la palabra "guerra" fuera tachada de la Convención.

Por último, la doctrina moderna sin duda alguna tiende a la eliminación de la distinción entre la guerra y otras formas de conflicto armado en lo que concierne los derechos de las víctimas. $\mathrm{La}$ guerra obviamente tiene un significado formal y otro genérico. El primero puede ser pertinente con respecto a cuestiones de derecho internacional concernientes a las relaciones diplomáticas, la suspensión de ciertas obligaciones bilaterales entre los beligerantes, los derechos $\mathrm{y}$ deberes de neutrales vis a vis beligerantes, o el tratamiento que ha de otorgarse a los nacionales y propiedad del enemigo. ¿Pero qué relevancia tendrá para el derecho internacional de los derechos humanos? Aún los principios fundamentales del derecho de la guerra, codificados en las Convenciones de Ginebra de 1949, estipulan que, para el propósito de dar protección a los individuos directamente afectados por las guerras, no debe de hacerse ninguna distinción entre la guerra, "cualquier otro conflicto armado" de tipo internacional o aún la ocupación no-resistida del territorio extranjero (7). Además, aunque los esfuerzos para desarrollar un código global de derecho humanitario para conflictos armados internos sólo dieron fruto en 1977 con la adopción del Protocolo II a las Convenciones de Ginebra, ya en 1949 una protección limitada fue extendida a los civiles afectados por conflictos no-internacionales por el Artículo Común 3 de las Convenciones (8).

En el clásico tratado de Pictet sobre los Convenios de Ginebra, Siordet opina que la extensión de esta protección a las victimas de conflictos que no califican como guerras y a conflictos internos era uno de los logros más importantes de las Convenciones de Ginebra:

(7) Los Convenios de Ginebra, Art. 2 Commun.

(8) Véase Montealegre H. La Seguridad del Estado y los Derechos Humanos, Santiago de Chile, 1979. Capitulo 26. 
"Hasta los tiempos recientes la guerra normalmente fue precedida por un ceremonial diplomático formal. Antes de acudir a las armas, habia una declaración de guerra de parte de una de las partes opuestas, seguida por la inauguración de un estado de guerra por los dos beligerantes con todas las consecuencias legales que esto involucraba. Es obvio el peligro. Existian demasiados casos en que la legitimidad disputada del gobierno enemigo, o la desaparición temporal de estados soberanos como resultado de la anexión o la capitulación, habia sido invocadas como pretextos por no observar una $\mathfrak{u}$ otra de las Convenciones. La necesidad de una solución a esta situación se habia vuelto urgente. Además, el desarrollo en toda la concepción de convenciones humanitarias señalaba exactamente lo mismo" (9) (traducción libre).

Si tal tendencia a restar importancia a la distinción entre la guerra en el sentido clásico y la guerra en el sentido genérico de la palabra ya estaba tan avanzada por ahí de 1949, ¿qué razones hay para pensar que los autores de los Pactos de Derechos $\mathrm{Hu}$ manos tenian la intención de usar el término en el sentido restringido?

Como ya se señaló, tampoco existe razón para pensar que la ausencia de una mención expresa de la guerra en el artículo que reconoce el derecho a la suspensión impide la suspensión por este notivo. El término "guterra" no figura en el Artículo 4 del Pacto Internacional porque se consideró que usarlo no concordaria con el objetivo de las Naciones Unidas de "abolir para siempre el flagelo de la guerra" (10). Como señala Buergenthal, sin embargo, "la omisión de una referencia especifica a la guerra seguramente no tenía el propósito de negar el derecho a la suspensión en tiempos de guerra puesto que la guerra es el ejemplo más dramático de una emergencia pública que puede amenazar la vida de la nación". Hasta ahora no hay ninguna jurisprudencia al respecto.

De las 158 convenciones de la Organización Internacional del Trabajo vigentes, solo dos, Convención 29 sobre el Trabajo Forzoso y Convención 106 sobre el Descanso Semanal, se refieren

(9) Siordet, F. en Pictet, Commentary I Geneva Convention, CICR. Ginebra, 1952, pág. 28.

(10) UN doc. A/2929 párr, 39. 
explicitamente a la guerra como motivo de la no aplicación de las normas internacionales de la OIT. La posición de la Secretaria de la OIT sobre la suspensión de las convenciones en tiempos de guerra fue desarrollada en un memorándum sometido en 1945 al máximo ente de la organización, el Consejo de Administración. En lo pertinente el documento dice:

"En la época moderna la intención de las partes generalmente se considera como el criterio que determina si las obligaciones de tratados entre beligerantes opositores sobreviven un estado de guerra. En el caso de instrumentos multilaterales que imponen reglas de carácter legislativo, existe una fuerte presunción de que la guerra entre ciertas partes no se entiende como anulando las obligaciones bajo el instrumento de ninguna de las partes, pero las obligaciones que resultan del instrumento en ciertos casos quedarán suspendidas entre beligerantes opuestos durante la guerra, y en relación a co-beligerantes y neutrales, un beligerante será eximido por la duración de la guerra de cumplir con todas las obligaciones bajo el instrumento que sean incompatibles con su posición como beligerante o que le sea imposible cumplir por force majeure. Estos principios generales parecerian aplicarse plenamente el caso especial de las Convenciones internacionales de trabajo. No parece haber ningún motivo para considerar que las obligaciones que resultan de las Convenciones sean anuladas ni siquiera entre beligerantes opuestos por la existencia de un estado de guerra, pero muchas de estas obligaciones sí deben ser consideradas como en estado de suspensión entre los beligerantes opuestos por la duración de la guerra.

Frente a co-beligerantes, neutrales y la Organización, los beligerantes partes a Convenciones parecerian estar eximidos de todas las obligaciones que les sea imposible cumplir por force majeure.

Esto es evidente en el caso de las Convenciones que contienen cláusulas que autorizan expresamente la suspensión de sus disposiciones en caso de guerra u otra emergencia nacional, en cuanto a otras convenciones, la aplicación de principios generales pareceria dar un resultado similar en el caso de la guerra" (11).

(11) Buergenthal, T. "To Respect and to Ensure: State Obligations and Permissible Derogations" en The International Bill of Rights: The Co- 
Como explica el autoritativo Código Internacional del Trabajo, aunque el Consejo de Administración no tomó acción explicita respecto al memorándum "las posiciones que figuran en él pueden ser consideradas como habiendo sido generalmente aceptadas; la práctica subsiguiente de la Organización ha sido basada en ellas" (12).

\section{3 ¿Cuándo Termina un Estado de Excepción Motivado Por la Guerta?}

Dos interrogantes más dificiles también surgen respecto a la guerra como motivo de la suspensión, y suelen tener una relevancia especial para América Latina hoy dia y para América Central en particular. Primero, ipuede el derecho a la suspensión ser invocado por una nación que no sea parte en la guerra o conflicto armado en cuestión? y segundo. ipuede el derecho a la suspensión extenderse después de terminadas las hostilidades? (13).

Ni los tratadistas ni la jurisprudencia de los órganos de los sistemas Americano y" Universal da mucha luz a esos problemas. Felizmente dos decisiones de la Comisión Europea de Derechos Humanos si hacen unas contribuciones doctrinales que ayudan a esclarecerlos (14).

El Caso De Becker trata de un civil condenado por un Conseil de Guerre belga en julio de 1946 por traic'ón durante la Segunda Guerra Mundial. Aunque las hostilidades habian terminado en junio de 1945, el estado de guerra siguió en vigencia en Bélgica hasta jun:o de 1949. De Becker fue condenado inter alia por "haber participado en la transformación de instituciones u organizaciones por parte del enemigo, por haber minado la lealtad de ciudadanos belgas al Estado en tiempo de guerra, por haber dirigido la propaganda contra resistencia al enemigo, por haber incitado a los

venant on Civil and Political Rights, Henkin, ed., New York 1981, pág. 79.

(12) Véase Convenios y Recomendaciones Internacionales de Trabajo, OIT. Ginebra.

(13) "Efectos de la Guerra sobre Convenios de la OIT", en El Código Internacional de Trabajo, Ginebra, 1957

(14) Id. 
ciudadanos a levantarse en armas contra la patria y por haber proporcionado tropas y obreros a los enemigos del Estado" (T.N.)

Inicialmente le fue impuesta la pena de muerte lo que más tarde fue conmutado a condena perpetua, y luego a 17 años de prisión. Antes de expirar este último término, le pusieron en libertad bajo condición de que residiera en el extranjero y que se abstuviera de actividad política durante el resto de los 17 años de la condena. Además, una ley especial privó a él y a toda persona condenada por delitos similares, ciertos derechos políticos, el derecho a enseñar o editar, y el derecho a ejercer ciertas profesiones en perpetuidad. De Becker no contestó ni la condena por sí ni el procedimiento del Conseil de Guerre. La principal cuestión sometida a la Comisión Europea era la legitimidad de la privación permanente de esos derechos, sobre todo la libertad de expresión.

El gobierno se amparó esencialmente en tres argumentos para justificar la ley: que la privación de los derechos de estos individuos se justificaba de manera general por la necesidad de disuadir semejante conducta en el futuro; que las restricciones a la libertad de expresión en particular se justificaban por el violento odio del público en contra de los culpables de traición durante la guerra, y que la privación de los derechos había sido justificada al momento de imponerse en razón de una emergencia pública y no podia pretender que la revocara sólo en razón del transcurso del tiempo. El Consejo de Ministros de Bélgica hizo la siguiente declaración en explicación de la adopción de las leyes en cuestión:

"el goce de los derechos de los c:udadanos belgas garantizados por la constitución y las leyes del Estado se basa en la fidelidad a la comunidad política que los protege. Esta fidelidad debe seguir demostrándose durante la crisis moral vivida por una nación en guerra cuyo territorio está invadido por el enemigo. A los que han traicionado su patria, hay que colocarles completa y rápidamente en una posición desde la que ya no pueden hacer más daño" (16) (T.N.)

(15) Caso De Becker, C.E.D.H. Serie B., 1962, págs. 21-22.

(16) Ibid, págs. 114 115. 
Puesto que la Convención Europea de Derechos Humanos no entró en vigencia hasta 1955, no competia a la Comisión considerar la legitimidad de "medidas de guerra" aplicadas hasta 1949 , o sea cuatro años después del fin de las hostilidades. Sin embargo, la Comisión unánimemente, y algo precipitadamente dado las profundas implicaciones de su conclusión, rechazó el argumento del gobierno de que medidas originalmente justificadas por la exis tencia de una guerra no deberian necesariamente perder toda vigencia en razón del fin de un conflicto:

"En la opinión de la Comisión, el Artículo 15 de la Convención no se puede aplicar al caso presente, dado que sólo se puede invocar en dos circunstancias bien defínidas: la guerra y cualquier 'otra emergencia pública que amenace la vida de la nación'. El Gobierno de Bélgica nunca ha pretendido que ninguna de estas situaciones haya surgido durante el periodo después del 14 de junio de 1955 , el cual fue el único periodo para ser considerado en la solicitud del Sr. De Becker.

"Sin embargo, el Gobierno de Bélgica si ha sostenido que las medidas de guerra, originalmente justificadas bajo el Articulo 15, no podrian dejar de estar vigentes automáticamente una vez terminada la guerra.

La Comisión siente no poder respaldar este argumento. El párrafo 3 del Artículo 15 claramente significa que las medidas de suspensión que dispone ünicamente se justifican bajo las circunstancias definidas en el párrafo 1 , con el resultado de que representan una contravención de la Convención si quedan vigentes después de que desaparezcan esas circunstancias" (17) (T.N.).

La Comisión también señaló que la extensión de los efectos de las medidas de emergencia más allá del fin de la emergencia misma podría constituir una violación del Articulo 18 de la Convención, la cual dispone que las restricc:ones a los derechos y libertades reconocidas por el instrumento "no se aplicarán para ningún propósito que no se encuentre entre aquellos para los que fueron prescritos".

(17) Ibid, pág. 133. 
Sin embargo, la Comisión sí reconoció que podría darse un estado de emergencia después del final de una guerra:

"Durante una guerra y durante el periodo inmediatamente después de terminar una, consideraciones sobre el estado de ánimo del pueblo y orden público pueden justificar que personas condenadas por asociaciones traidores con el enemigo sean sometidas por el Estado a la privación total o casi total de su libertad de expresión. Además, cuando un país ha vivido un largo periodo de ocupación por el enemigo con todos sus efectos en el ánimo público, puede ser que el proceso de restauración del ánimo del público y el riesgo de perturbaciones al orden público haga necesario $\mathrm{y}$ justifique la plena aplicación de estas incapacidades por algún periodo de tiempo después de la terminación de hostilidades" (18) (T.N.).

Sin embargo, una vez pasado el periodo de la emergencia reconocido por el Artículo 15, sólo se puede justificar la continuación de medidas especiales en la medida que caben dentro del alcance de las restricciones permitidas en tiempos normales para proteger el orden público y la seguridad nacional. En el caso en cuestión, la Comis'ón falló que la suspensión permanente y generalizada de la libertad de expresión de personas condenadas por traición no es aceptable como una medida para prote. ger la seguridad nacional y el orden público en una sociedad democrática.

Poco después de que el caso llegó a la Corte Europea de Derechos Humanos para una decisión final, se aprobó una ley limitando la suspensión de la libertad de expresión de personas como De Becker a escritos en "publicaciones de carácter politico". Con base en tal enmienda, la Corte estimó innecesar:o proceder a examinar el fondo del fallo de la Comisión (19).

La OIT también se ha referido a la cuestión sobre el momento en el cual suspensiones por causa de guerra quedan sin vigencia.

(18) Ibid.

(19) C.E.D.H., Serie A. 1960-68, Caso De Becker, Fallo de 27 marzo, 1962. 
El memorándum antes citado, "El Efecto de la Guerra sobre convenios de la OIT" declara que "puede considerarse que el fin de una guerra termina automáticamente la suspensión de obligaciones..." (20). También reconoce, sin embargo, que "la situación de facto en cuanto a la aplicación de estas obligaciones suele ser altamente insatisfactoria después de la guerra a menos que se tome acción apropiada al fin de la guerra, para asegurar que las obligaciones que juridicamente sobreviven se hagan efectivas otra vez... Han de tomarse medidas apropiadas lo más pronto posible para reanudar la aplicación normal de las obligaciones provenientes de las Convenciones ratificadas por los Miembros de la Organización que hayan sido beligerantes o que hayan invocado cláusulas contenidas en ciertas Convenciones que permitan la suspensión en caso de una emergenccia nacional" (21) (traducción y subrayado nuestro).

En la supervisión los derechos de los trabajadores reconocidos internacionalmente, el quasi-judicial Comité de Libertad Sindical ha afirmado la importancia de que "la reglamentación de guerra fuera reemplazada tan pronto como sea posible después de la conclusión de las hostilidades por una legislación que garantice a los sindicatos mayor libertad de acción (22) (subrayado nuestro). Asi que, aunque los pronunciamientos de la OIT sobre esta cuestión no reconocen explícitamente el concepto de una emergencia posguerra como la descrita por la Comisión Europea en el Caso De Becker, hasta cierto punto se reconoce que un periodo de transición podria ser necesario antes de que se pueda esperar el cumplimiento total con las normas internacionales.

En conclusión, principios generales que deberian de aplicarse con respecto a las suspensiones durante épocas de guerra en América Latina, serian estos: Primero, las medidas de guerra strictu sensu deben terminar automáticamente con el fin de las hostilidades, o a más tardar después de un brevísimo periodo de transición que no sobrepase lo estrictamente necesario para adop-

(20) Supra, pág. 7 .

(21) Id.

(22) La Libertad Sindical recopilación de Decisiones del Comité de Liber tad Sindical (2a edición) Ginebra, 1976 para 336. 
tar las medidas legislativas $\mathbf{y}$ administrativas requeridas para poner fin a las medidas de guerra. Segundo, la prolongación de poderes de emergencia en el periodo de posguerra se justifica únicamente por la existencia de una emergencia en el sentido definido por el instrumento internacional pertinente durante este periodo. Es decir, han de ser basado en una amenaza a la nación - a la independencia y seguridad del Estado que resulta de las caracteristicas particulares del periodo de posguerra, y por lo tanto deben ser diseñadas especificamente para enfrentar las características de tal periodo, no las del periodo anterior del conflicto armado. Tercero, una vez que haya disminuido la crisis posguerra y se haya eliminado o reducido a proporciones normales la amenaza a la seguridad nacional y el orden público, cualquier descalificación, discriminación o restricción a los derechos que surja de la emergencia y que continúe, es legítima solamente en la medida en que no sobrepase las restricciones reconocidas por las normas internacionales en tiempos normales.

Estas conclusiones, por supuesto, se basan en la hipótesis de una guerra real, ya sea una guerra civil como la revolución nicaragüense, o un conflicto internacional, pero no de una guerra ficticia como las que han sido invocadas en más de un pais del Cono Sur para justificar un estado de emergencia. De la misma manera no pretende que se pueda presumir la existencia de una emergencia en el periodo después del fin de hostilidades, pues en muchos casos tal emergencia no se dará.

\subsection{Los Efectos de Conflictos Armados en Paises Neutrales}

La pregunta final es si la guerra puede justificar la suspensión de las normas de derechos humanos en una nación nobeligerante. $\mathrm{El}$ antecedente más pertinente al respecto, aunque el criterio invocado no es el de guerra sino de "otra emergencia públi, ca", es la decisión de la Comisión Europea en el Caso Lawless. En este caso un estado de emergencia en la República de Irlanda fundamentó en la existencia en tal país de una organización paramilitar dedicada al derrocamiento del gobierno de un territorio vecino. Irlanda del Norte. Aunque no se estableció el nexo entre el IRA y una amenaza a la vida del pais anfitrión de manera realmente concluyente (una falta subrayada en las cinco opinio- 
nes disidentes) este antecedente ayuda a identificar por lo menos una nación podría tener derecho de suspender sus obligaciones en materia de derechos humanos en razón de un conflicto armado en un Estado vecino; a saber, el uso de su territorio por una o más de las fuerzas armadas involucradas en el conflicto. Es posible que la llegada masiva de refugiados o la obstaculización del abastecimiento de provisiones vitales por causa de una guerra en un Estado vecino por ejemplo también podria justif:car un estado de emergencia, siempre que se demuestren consecuencias suficientemente graves y la necesidad de las medidas excepcionales especificas.

Una variante más compleja de esta interrogante es saber si la obligación de cumplir con los deberes de un poder neutral o con las obligaciones internacionales de samejante carácter podria justificar la suspensión de obligaciones sobre la protección de derechos humanos. El derecho humanitario impone a los Estados neutrales por ejemplo deber de guardar en detención hasta el fin de la guerra las tropas de uno u otro poder beligerante que entren en su territorio (23). Diecisiete Estados Latinoamer canos son Estados Partes a la Convención de 1928 sobre los Derechos y Deberes de Estados en Casos de Lucha Civil, en virtud de la cual se reconoce expresamente este mismo deber de detener hasta el fin del conflicto las fuerzas que participan en una guerra civil y' que entran en el territorio de una nación neutral (24).

Otra vez es la jurisprudencia del sistema Europeo la que nos proporciona unas directrices que ayuden a desenmarañar el problema. En el caso Lawlees, si bien no se pretendió que una verdadera guerra existiera en Irlanda del Norte en aquel entonces, lo cierto es que el Sr. Lawlees fue detenido bajo poderes de emergencia en la República de Irlanda por causa de su participación en actividades bélicas dirigidas contra el pais vecino. La

(23) V Convenio de la Haya, Art. 11. Véase tambien Tomo 11, Digest of International Law, Washington, 1968, pág. 336.

(24) Conferencias Internacionales Americanas 1889-1936, Washington, 1938, pág. 388. para consultar estado de ratificaciones véase Tratados y Convenios Interamericanos, Washington, 1980, pág. 29. 
Comisión Europea enfatizó en su decisión, las consecuencias para las relaciones de Irlanda con su vecino si su territorio seguia siendo aprovechado como base para actividades paramilitares. Sin embargo, afirmó que:

"El Gobierno demandado está justificado en su contención de que, al tener conciencia en julio de 1957, de la existencia de una emergencia pública que amenazaba la vida de la nación, tenía derecho de dar un peso substancial a sus obligaciones bajo el derecho internacional para impedir que su territorio fuera usado como una base para ataques contra un territorio vecino. Según el derecho internacional general era el claro deber de la República servirse de los medios de que disponia para impedir, e impedir totalmente, que su territorio fuera usado como base para incursiones armadas en Irlanda del Norte" (25) (T.N.)

A este argumento se añadió la observación que, siendo Irlanda y el Reino Unido Estados Miembros de la misma organización regional politica y Estados Partes en el mismo tratado sobre derechos humanos, tienen esos paises:

"una responsabilidad especial entre si con respecto a actividades ilegales en territorio propio que amenacen el goce de los derechos humanos y libertades fundamentales en el territorio de otro Miembro. Por lo tanto concluimos que el hecho de que los pueblos de Irlanda del Norte, igual que los de la República de Irlanda, se encuentren dentro de la Comunidad del Consejo de Europa y bajo la protección de la Convención Europea sobre Derechos Humanos es otra razón de peso para que el Gobierno de la República no pudiera cerrar los ojos frente al riesgo de que las actividades ilegales de sus súbditos causaran una erupción de contienda civil en el territorio contiguo" (26) (T.N.)

Sin duda alguna uno de los puntos débiles de la decisión de la Comisión es la idea de que el riesgo de que se deterioren las relaciones entre Irlanda y el Reino Unido constituia por si un "peligro a la vida de la nación". Como declaró el Sr. Süs-

(25) Caso Lawless, (supra, nota 6), pág. 88 .

(26) Ibid, pág. 89. 
terhenn en su opinión disidente, "los actos de violencia que el IRA ordena que se lleven a cabo en Irlanda del Norte desde sus bases en Irlanda del Sur, si son calculados para entorpecer las relaciones amistosas entre la República de Irlanda y el Reino Unido. Sin embargo, es imposible sostener que de eso pudiera surgir un verdadero peligro de guerra entre la República de Irlanda y el Reino Unido... Seria irrazonable contemplar la posibilidad de un conflicto armado" (27) (T.N.)

Otro miembro disidente de la Comisión, el Dr. Dominedo. comentó este punto aún más tajantemente al decir: "No se puede hablar en serio de un peligro de guerra extranjera. Eso sería una alegación imaginaria cuando todos conocen muy bien el verdadero carácter de las relaciones entre Irlanda y el Reino Unido..." (28). En una hábil paráfrasis de la opinión del Sr. Süsterhenn, una comentarista afirmó que "las tensiones diplomáticas no representan ninguna amenaza seria de guerra" (29).

Esa clase de conflicto entre normas internacionales sobre derechos humanos y otras obligaciones en el derecho internacional de lo cual un buen ejemplo se encuentra justamente en que el derecho de los derechos humanos no acepta la detención sin juicio mientras el derecho humanitario establece el deber de detener a las fuerzas armadas que entren en territorio neutral ha recibido poca atención de parte de los tratadistas. El análisis que tal conflicto merece, excederá en mucho el alcance del presente trabajo. Sólo puede decirse que ninguna de las dos obligaciones suele tener carácter de jus cogens, lo cual indicaria claramente cuál tendria jerarquía sobre el otro. Tampoco está pre visto explicitamente este tipo de conflicto por la Convención de Viena sobre el Derecho de los Tratados ni por las cláusulas de los tratados sobre derechos humanos que se refieren a la relación de ellos con otras normas juridicas internacionales.

(27) Ibid, pág. 96

(28) Ibid, pág. 100.

(29) Hartman, Joan "Derogations frcm Human Rights. Treaties in Pub!cic Emergencies: A Critique of Implementation by the Europea Commission and Court of Human Rights and the Human Rights Committee of the United Nations", Harvard International Law Journal, vol. 22 No 1. Winter 1981). 
En ausencia de tales directrices, parecería ser que una obligación conflictiva no justificaria la suspensión de obligaciones I ara la protección de derechos humanos a menos que coincida con las circunstancias expresamente reconocidas por los tratados sobre derechos humanos que preveen la suspensión. En otras palabras, al referirnos otra vez a la doctrina del caso de Irlanda del Norte, si bien es cierto que un Estado puede tener el deber de servirse de los medios de que dispone para prevenir ataques asmados contra paises vecinos, y quizás hasta deberes especiales de proteger (o por lo menos de cooperar en la protección) de los derechos de los residentes de Estados con los cuales tiene un vínculo especial por causa de ser ambos co-miembros de una comunidad política regional y por haber ratificado las mismas obligaciones sobre derechos humanos, a pesar de todo esto ha de interpretar este deber como el de usar las medidas normalmente disponibles en y consistentes con una sociedad de tipo democrático. Tal deber, aún si es un deber que surge únicamente en el contexto de una guerra, como es el caso del antes mencionado deber a detener a integrantes de una fuerza armada, no permite la suspensi6n de las obligaciones en materia de derechos humanos a menos que se dé la imprescindible amenaza a la vida de la nación o a la independencia y seguridad nacional.

Sin embargo, la falacia principal de la decisión Lawless, no es tanto la posición doctrinal sino la falta de pruebas congruentes con el análisis de la mayoría de la Comisión. Cuando el uso del terr torio nacional para organizar ataques contra un Estado vecino crea un riesgo real $e$ inminente de un conflicto armado internacional, desde luego existiria justificación para tomar medidas que suspenden las normas de derechos humanos. La distinción señalada por Hartman entre meras tensiones diplomáticas y la amenaza de guerra sirve como una prueba analitica útil. Por ejemplo si fuese necesar:o para Honduras suspender ciertas de sus obligaciones en materia de derechos humanos para impedir el uso de su territorio por fuerzas que lanzan ataques contra fuerzas gubernamentales en Nicaragua, el actual estado de relaciones internacional entre los dos paises pareceria justificar tal acción. Pero aunque hay tensiones diplomáticas entre Costa Rica y Nicaragua, no existe ningún peligro real de una guerra entre las dos naciones como para justificar la suspensión de obligaciones de derechos humanos en Costa Rica. 
Por supuesto no hay por qué limitar este principio a la circunstancia específica de un peligro de que el Estado neutral sea arrastrado hacia un conflicto armado ni a la circunstancia de que su territorio sea usado por una parte en el conflicto. Podrian también justificar la declaración de una emergencia otros tipos de consecuencias para un Estado neutral. Si una guerra en uno o más de los Estados vecinos amenaza los intereses económicos vitales de una nación neutral, esto quizá constituirá una amenaza a la vida de la nación tal como justificaria la suspensión de ciertas obligaciones de derechos humanos.

En conclusión, aunque es razonable presumir que el peligro que representa una guerra o conflicto armado en uno o más Estados vecinos para la vida de la nación o la independencia o seguridad del Estado normalmente es menor que el peligro que representa un conflicto actual o inminente en que el Estado está directamente involucrado, en cuanto a la legitimidad en derecho internacional de la suspensión de normas de derechos humanos no es la pregunta formal sobre si el Estado es parte o no al conflicto lo que es determinante, sino más bien los efectos reales de tal conflicto sobre la nación.

\section{PARTE II}

\section{AMENAZAS INTERNAS COMO MOTIVO PARA LA SUSPENSION DE GARANTIAS}

Con muy pocas excepciones, los estados de emergencia que han sido examinados hasta ahora por los tribunales internacionales competentes han surgido de alteraciones $o$ desórdenes internos. Sin embargo, aún con respecto a esta clase de estado de emergencia, son casi inexistentes las decisiones que abordan directamente la cuestión de saber si una determinada situación corresponde o no al concepto de emergencia pública tal y como está de definida por la Convención Americana o el Pacto Inter. nacional. Dentro de los sistemas juridicos que surgen de tales instrumentos las instancias internacionales correspondientes, cada 
una por sus propios motivos, se han concentrado en aplicar el principio de no-suspendibilidad de ciertos derechos, y en el caso de la Convención Americana, la cláusula de "garantías esenc'ales". Conviene por esta razón comenzar con la jurisprudencia de la Comisión y la Corte Europea.

\subsection{Jurisprudencia Europea: El Caso Lawless}

La jurisprudencia de los órganos de la Convención Europea consiste esencialmente de una trilogia de casos: la decisión de 1961 de la Comisión sobre el Caso Lawless; la decisión de 1969 de la Comisión en el Caso de Grecia; y su decisión en 1976 sobre el Caso de Irlanda del Norte (formalmente conocido como el caso de Irlanda vs. el Reino Unido) tal como fue modificado por la decisión de 1978 de la Corte Europea de Derechos Humanos. Un caso que se refiere al actual estado de emergencia en Turquia está pendiente ante la Comisón en este momento, y se espera que contribuya en gran medida a desarrollar la jurisprudencia Europea sobre estados de excepción.

Al igual que el Pacto Internacional, la Convención Europea usa el vocablo "amenaza a la vida de la nación", mientras que. la Convención Americana que se refiere a "amenaza a la independencia y seguridad del Estado". Cualquier discusión de la forma en que se ha aplicado tal concepto en el sistema europeo (todavia no ha sido aplicado por el Comité de Derechos Humanos bajo el Pacto Internacional) debe tomar como punto de partida el hecho de que esa expresión se ha convertido en un "término de arte", es decir, las palabras "amenaza a la vida de la na c'ón" no se pueden interpretar literalmente.

Irónicamente. esta evolución ocurrió con el Caso Lawless en donde la decisión de la Comisión comienza precisamente con la observación -aparentemente en contestación al erudito voto razonado del Sr. Eustathiades- de que no existe ninguna razón para atribuir a estas palabras otra cosa que su "significado literal y corriente" (30). Sin embargo, la misma decisión desmiente esta afirmación. Como hizo constar otro miembro disidente de la Co-

(30) Caso Lawless (supra, nota 6) pág. 82. 
misión, y con un candor no característico de los tribunales internacionales: "no es posible, si queremos quedarnos dentro de los limites de la realidad, decir que la misma vida de Irlanda esté en peligro. Me refiero tanto al Estado como a la Nación de Irlanda. Parece que cualquier hombre profano o persona responsable, sea irlandés o no, al examinar las cond'ciones actuales de la vida en Irlanda con objetividad, debe llegar a esta conclusión fundamental" (31). La ausenc:a de pruebas de una verdadera interrupción de la vida de la nación -la Comisión misma tuvo que reconocer que las actividades del IRA "tenían relativamente poco impacto en la vida cotidiana del público en general, excepto quizás en el área cerca de la frontera" (32) - y el hecho insólito de que "en diez años ni un solo disparo se había producido por razones politicas en el territorio de la República de Irlanda" (33). revelan un profundo abismo entre conclusión de la Comisión de que existia una "amenaza a la vida" y el "significado normal y corriente" de estas palabras.

Dados los problemas sociales y económicos que caracterizan de una forma $\mathbf{u}$ otra a todas las naciones de América Latina y que constituyen una fuente perpetua de alteraciones del orden público, la adopción de las normas fácticas empleadas en el caso Lawless podría bien significar la eliminación de todo limite a la discreción de los gobernantes en cuanto a la declaración de estados de emergencia. Realmente, en vista de los cambios que han ocurrido en el mundo entre 1960 y 1984, uno puede preguntarse si la situación que prevalecia en Irlanda al final de la década de los cincuenta se podría considerar causa suficiente para declarar un estado de emergencia en cualquier región del mundo. Hay que recordar que una de las razones por la cual la Comisión rehusó reconocer la legit:midad del estado de emergencia declarado por los Coroneles Griegos en 1967 fue precisamente que las alteraciones que estaban sucediendo en Grecia inmediatamente antes del golpe no eran apreciablemente más graves que las que se daban en varias otras sociedades europeas en el mismo período.

(31) Ibid. pág. 85 .

(32) Id.

(33) Ibid, pág. 95. 
La tipificación, los matices no fácticos sino juridicos de una amenaza a la vida de la nación fueron afirmados nítidamente por la Comisión en la siguiente y ahora famosa frase:

"El significado natural y corriente de una emergencia pública que amenaza la vida de la nación, es, según opinamos nosotros, una situación de peligro o crisis excepcional e inminente que afecta al público en general, y no solamente a algunos grupos en particular, y que constituye una amenaza a la vida organizada de la comunidad de que está compuesta el Estado en cuestión" (34).

Dos aspectos menos conocidos de la decisión de la Comisión también merecen ser analizados, a saber, la cuestión del terrorismo y las dimensiones psico-politicas de la situación de emergencia.

Sobre la cuestión del terrorismo, la Comisión declaró que:

"Nos parece que la mera existencia dentro de un Estado de una organización llegal que rehuse reconocer la autoridad legal del Gobierno elegido y que reclute y abastezca con armas una fuerza militar clandestina representa hasta clerto punto una amenaza a la vida de un Estado democráticamente organizado" (subrayado nuestro).

Aunque la Comisión afirmó que "puede haber opiniones diferentes" con respecto a si la mera existencia de un ejército terrorista constituye una amenaza a la vida de la nación (36), es importante el hecho de que la Comisión se sintió obligada a basar conclusión de que existia una situación de emergencia en dos factores; la existencia de tal organización armada ilegal más un minimo de actividad terrorista. En este caso, tal actividad consistió por un lado en el robo de armas y la intimidación de jueces y testigos en Irlanda, y por el otro en ataques armados contra la propiedad y la vida en un territorio vecino. Además,

(34) Ibid, pág. 82 .

(35) Ibid, pâg. 86-7.

(36) Ibid, pág. 87 . 
la Comisión afirmó que la existencia de la fuerza terrorista más el nivel de actividad terrorista observado en la República de Irlanda "contenia algunos de los elementos de una emergencia pública que amenaza la vida de la nación" (37) (Subrayado nuestro), lo cual implica que sin la dimensión internacional, el nivel de actividad terrorista en la República no hubiera sido suficiente como para justificar la suspensión de derechos. Asimis. mo al confirmar la decisión de la Comisión, la Corte Europea declaró que la existencia de una amenaza a la vida de la nación "fue razonablemente deducido por el Gobierno Irlandés de una combinación de varios factores, a saber: en primer lugar, la existencia en el territorio de la República de Irlanda de un ejército secreto empeñado en actividades anti-constitucionales y recurriendo a la violencia para lograr sus propósitos; en segundo lugar, el hecho de que este ejército también operaba fuera del territorio del Estado, poniendo asi en peligro las relaciones de la República de Irlanda con su vecino; en tercer lugar, el aumento constante y alarmante en las actividades terroristas, desde el otoño de 1956 y durante la primera mitad de 1957" (38). En esta formulación son de notar por una parte la referencia a una combinación de factores, y por el otro la expresa mención del aso de la violencia.

El aumento en actividades terroristas a que se refirió la Corte consistió principalmente en la explosión de bombas y tiroteos en Irlanda del Norte, lo cual viene a reforzar la conclusión que la actividad que tuvo lugar dentro del territorio de la República (el robo de armas y cierta intimidación de jueces y jurados) no hubiera justificado la toma de medidas de emergencia. La clara implicación de todo lo anterior es que una amenaza terrorista latente no es motivo suficiente para tomar medidas de seguridad que requieren la suspensión de obligaciones internacionales.

Otro aspecto relevante de la decisión de la Comisión es la importancia que atribuye a las dimensiones psicológicas y politicas de la crisis. En las circunstancias antes mencionadas, es decir el bajo nivel de conducta abiertamente delictuosa y la relativa

(37) Id.

(38) C.E.D.H. Serie A. 1960-61, Caso Lawless, Fallo de 14 noviembre, 1960, pág. 56. 
ausencia de verdaderas alteraciones del orden público, la Comisión se vio obligada a poner cierto énfasis en las dimensiones psicológicas y politicas de la crisis en aras de justificar la conclusión de que una amenaza real e inminente existia. Declaró por ejemplo:

"Si el Gobierno de la República, cuyos súbditos estaban usando su territorio para lanzar una lucha guerrillera contra Irlanda del Norte, no trataba la grave situación que habia surgido también como una de emergencia pública, podria razonablemente temer que se les hubiera sospechado de ser tibio en sus esfuerzos para controlar al IRA, y esto con consecuencias muy serias.

El Gobierno demandado además argumentó en la SubComisión que también habia sido influenciado por el temor de que, si los ataques del IRA no se paraban pronto, grupos protestantes en Irlanda del Norte podrian tomar represalias contra la población católica, el elemento de la población que más simpatiza con los fines de la organización paramilitar IRA. El Gobierno declaró que sus temores sobre este aspecto se basaban en amargas experiencias pasadas de tales sucesos, y que creia muy real el peligro de que se repitieran" (39).

La cuestión de si existen emergencias de naturaleza politicas, en el sentido de que medidas de emergencia podrían adoptarse legitimamente para objetivos esencialmente políticos o psicosociales, es de considerable importancia en América Latina. Sobran ejemplos de tentativas de justificar medidas represivas invocando la necesidad de mostrar firmeza con un movimiento de oposición ilegal, para combatir la inseguridad o falta de confian$z a$ en el manejo de asuntos públicos o para erradicar las "raíces" de la subversión. Esto suele suceder especialmente cuando se recurre a poderes excepcionales para responder a una amenaza "latente" o cuando aquellos se extienden más allá de la duración de una verdadera crisis.

Sería irrealista sugerir que una supuesta emergencia deberia de evaluarse en términos puramente objetivos - por ejemplo sumando el número de incidentes terroristas y contrapesando de manera 
cuasi aritmética la fuerza y la eficacia de med das represivas sin evaluar el nivel de rechazo de las medidas de represión o apoyo activo o pasivo de que goza el terrorismo en la opinión pública. Sin embargo. el peligro es que la evaluación de factores sujetivos llega a asumir una importancia superior a la de la amenaza rea! y objetiva que representa la actividad delictuosa abierta.

En el Caso Lauless, los miembros disidentes de la Comisión comentaron este mismo problema. "Cnn respecto a la posibilidad de que se extiendan las actividades del IRA" dijo el Sr. Eustathiades:

"cualquier conclusión basada en una investigación de la situación... debe fundarse únicamente en hechos existentes, y no puede tomar en cuenta predicciones sujetivas relativas a la evolución futura o temores unilaterales de que la situación se degenere y la amenza aumente (estos temores, además, equiparados de antemano con la emergencia excepcional en la disposición del Artículo 15 de la Convención... )" (40).

Con respecto especificamente a la dimensión internacional de la situación la Sra. Janssen-Pevtschin declaró:

"estas consideraciones son esencialmente conjeturales $e$ hipóteticas; no son respaldadas por ninguna evidencia..." (41).

Un tercer disidente, el Sr. Dominedo, op:nó que:

"Sin embargo es obvio que examinar [sólo] los hechos materiales no es suficiente; ellos han de ser analizados también a la luz de sus causas; es decir, los motivos psicológicos y morales que los provocan" (42).

En base a esto, llega a la conclusión bastante radical de que los motivos nacionalistas del IRA surgirian (aunque no comprobaban por sí mismo) de una amenaza a la vida de la nación. "El deseo de lograr la unidad étnica de su propia nación",

(40) Ibid, pág. 94.

(41) Ibid, pág. 101.

(42) Ibid, pág. 99. 
escribió, "no puede significar la voluntad de dañar la vida de esa nación" (43).

En una análisis algo mejor razonado, el Sr. Süsterhenn enfatizó no los motivos del ERI sino su estrategia. Observó, por ejemplo, que a los miembros del ERI les fue prohibido formalmente que tomaran "cualquier acción militante" en la República de Irlanda "bajo circunstancia alguna" (44). Concluye el Sr. Süsterhenn que esta estrategia, dado la ausencia de ataques armados dentro del territorio por un periodo de años, (o sea el cumplimiento de aquella) demostraba que efectivamente no existia "ninguna razón para diagnosticar un peligro inmediato de que el ERI se empeñara en actos revolucionarios contra el Gobierno Irlandés, y que asi amenazara la vida de la nación". Para él, más bien, evidenciaba "una amenaza potencial al orden constitucional de la República de Irlanda" (45) (subrayado nuestro).

\subsection{El Caso Lawless: Los Votos Razonados}

Más de veinte años después, las opiniones disidentes de los Sres. Eustathiades y Süsterhenn presentan todavia quizás el análisis más lúcido que se haya publicado sobre estados de emergencia, así merece que se mencione otros detalles mas de sus votos razonados.

El Sr. Eustathiades atribuyó considerable importancia a las diferentes funciones de las disposiciones sobre la suspensión y las cláusulas de restricción, las cuales, en la Convención Europea asi como en la Americana permiten que ciertos derechos sean restringidos por razones de seguridad nacional $y$ orden público, entre otras. Observa que:

"La Convención misma hace una distinción muy clara, al referirse en una serie de Artículos, tal como en el segundo párrafo de Artículos $8,9,10$, y 11, a las amenazas al orden público o a la seguridad que justifican restricciones a ciertos derechos garantizados por la Convención: mientras que el tipo de situación a que se re-

(43) Ibid, pág. 100.

(44) Ibid, pág. 97.

(45) Ibid, pág. 97-8. 
fiere el Articulo 15 es de una gravedad totalmente excepcional, que justifica no solamente la imposición de restricciones sino también la suspensión de los términos de ciertos Articulos que protegen los derechos humanos" (46).

Al analizar la historia de los entremezclados procesos de redacción de la Convención Europea y del Pacto Internacional, concluye que el reconocimiento del derecho de los Estados Partes a declarar la suspensión,

"fue retenido en el texto del proyecto como una disposición para enfrentar una situación de carácter muy excepcional, mucho más seria que cualquier amenaza al orden público y a la seguridad cubierta por las cláusu. las de restricción" (47).

Sostiene además que el uso de la palabra "otra" significa que la amenaza a la vida de la nación ha de ser "de carácter tan excepcional como la guerra". Recordando que la expresión "que amenaza la vida de la nación" vino a sustituir al vocablo "que amenaza los intereses del pueblo" (48), enfatiza que la forma en que dicho principio finalmente fue redactado y adoptado.

"se basó en el concepto que la emergencia pública deberia ser de tal magnitud como para amenazar la vida de la nación entera... Se pensó que la referencia a una emergencia pública que amenazara "la vida de la nación" evitaría cualquier duda sobre si la intención fue de referirse a todo o a solo una parte del pueblo "(49) (subrayado nuestro).

La primera parte de su análisis concluye con la siguiente observación:

"En general, el trabajo preparatorio del Articulo $15 y$ sus antecedentes demuestran que se usa la palabra "ná-

(46) Ibid, pág. 90.

(47) Ibid, pảg. 91-2.

(48) Ibid, pág. 92.

(49) Id. 
ción" para aclarar que se refiere a una amenaza a la existencia de la población entera que surge de alguna emergencia particularmente grave que excede en mucho cualquier problema de orden público y seguridad que surja en otras circunstancias" (50).

En la segunda parte de su opinión se refiere esencialmente a la situación real que prevalecia en Irlanda. Dice al respecto:

"Los hechos demuestran, sin embargo, que el Gobierno, Parlamento y Tribunales Irlandeses están funcionando normalmente; no parece haber ningún aumento excepcional en la delicuencia; el número de victimas de las actividades del IRA no es muy grande, y el cuadro general en este momento (las actividades del IRA mencionadas en los alegatos del Gobierno Irlandés del 12 de enero de 1959 pertenecían a otro período) contiene a lo máx:mo un riesgo de alteraciones localizadas, mientras los problemas creados por la partición de Irlanda han existido desde el momento en que esta partición se efectuó" (51).

En este párrafo, se perciben dos conceptos criticos: primero la idea de que el funcionamiento normal del gobierno es el criterio para juzgar si una situación es tan "excepcional" como para justificar la suspensión, $y^{n}$ segundo, la insistencia en que una amenaza debe ser presente o inminente, no simplemente futura o potencial.

El voto razonado del Sr. Süsterhenn tocó muchos de los mismos puntos. En cuanto a la referencia a la guerra en el Artículo sobre suspensión, sostuvo que los autores de la Convención tenian presente la Segunda Guerra Mundial y que la intención era que el término se refiriera a combates militares internacionales "tan intensivos y extensos que representarán una verdadera amenaza a la existencia del Estado" (52), (subrayado nuestro).

(50) Ibid, pág. 93.

(51) Id.

(52) Ibid, pág. 95. 
Aún el uso de una "quinta columna" para destruir o sabotear instalaciones o comunicaciones en el territorio de otro Estado, según afirmó, no sería:

"equivalente a la guerra mientras los actos de sabotaje se cometieran en una área fronteriza y no pertubaran la economia general del Estado afectado" (53).

Aunque la situación en Irlanda del Norte no constituia un conflicto armado entre Estados soberanos, el térm'no "u otra emer. gencia pública" indicaba sin embargo que el concepto tradicional dé la guerra total es el indice de gravedad al que una situación debe llegar antes de que la suspensión de la Convención puede considerarse legitima.

También enfatizó la importancia de alteraciones concretas del orden público como prueba de la existencia de una verdadera emergencia:

"No hay duda de que la vida de todos los sectores - a politica, la economia, el transporte, la educación y la prensa- sigue igual que siempre en la República de Irlanda. Lo mismo es cierto de la administración de justicia. En todo caso, parece desprenderse de las declaraciones dadas por ambas Partes que, en general, no hay ninguna interferencia con el orden público y la seguridad en la República de Irlanda. Ambas Partes reconocen, en particular, que por diez años ni un sólo disparo se ha hecho por razones políticas en el territorio de la República de Irlanda" (54).

Un tercer miembro de la Comisión, el Sr. Emacora, señaló lo mismo;

"Las acciones del IRA no alteraron ni la vida cotidiana ni la vida del Estado. Según los principios del derecho público municipal, un estado de emergencia (Notstand) existe si ya no es posible aplicar las reglas constitucionales, $o$ en otras palabras cuando la asamblea legislativa, el poder judicial y la administración ya no

(53) Id.

(54) Id. 
están funcionando. Pero así no fue el caso durante el periodo en cuestión" (55).

Asi el hecho de que un gobierno tenga en la realidad la posibilidad de controlar amenazas potenciales por métodos ordinarios - sean policiacos, socio-politicos o una combinación de ambos - excluye definitivamente la conclusión que hay un real e inminente peligro a la vida de la nación.

Como ya se ha mencionado, el Sr. Süsterhenn lleva este análisis más allá y argumenta que la estrategia de una organización ilegal como el IRA, o sea limitaciones subjetivas o auto-restricciones, son relevantes para la determinación del tipo de amenaza que una organización representa para la vida de la nación. La decisión politica de no recurrir a la acción armada contra la República de Irlanda, por lo menos en el contexto del cumplimiento con dicha politica, significaba que la existencia de una organización para-militar secreta y bien armada no constituia más que una amenaza potencial a la nación. Como veremos, este punto de vista fue adoptado más tarde por una mayoría de la Comisión en el Caso de Grecia (56).

Finalmente, la opinión del Sr. Süsterhenn se destaca por su insistencia en la distinción entre amenazas reales o inminentes y amenazas latentes o potenciales y el concepto de transcendental importancia de que las primeras implican un deterioro reciente y drámatico de la situación. En la siguiente cita explica la distinción con nitidez:

"Al evaluar la situación general en la República de Irlanda, asi también como las relaciones entre la $\mathrm{Re}$ pública y el Reino Unido, no podemos negar categóricamente la existencia de una amenaza potencial que puede resultar en una amenaza a la vida de la nación en el futuro. Puesto que todo gobierno tiene un cierto margen de apreciación para juzgar si la vida de la nación queda amenazada por una emergencia o no, reconocemos el derecho del Gobierno Irlandés de argumentar que existe una tal emergencia y de considerarla

(55) Ibid, pág. 101.

(56) Ibid, pág. 97. 
como muy grave. Hay que reconocer, sin embargo, que la emergencia es sólo potencial, que se ha mantenido durante años sin cambio apreciable ninguno y que ha conducido a ninguna alteración seria del orden público general ni de relaciones externas. Por eso no se puede considerar como de una gravedad excepcional, sino solamente como una emergencia latente de un grado menor" (57).

\subsection{El Caso de Grecia}

De primera vista, el Caso de Grecia parece ser nada más que una aplicación de los principios anunciados en el Caso Lawless a una nueva situación fáctica. En contraste con este, no hubo debate substancial entre los miembros de la Comisión sobre la interpretación que se ha de dar al texto del Artículo 15. Sin embargo, en realidad el Caso de Grecia representa un avance importante en la jurisprudencia de la Comisión Europea respecto a la definición de una emergencia que amenaza la vida de la nación.

Primero, la Comisión clarificó cierta confusión que habia quedado respecto a si el elemento de inminencia era o no una parte de la definición de una emergencia formulada en el Caso Lawless. La palabra figuraba en la decisión de la Comisión y en la versión en francés de la decisión de la Corte, pero no en la versión en inglés de éste. En el Caso de Grecia la Comisión señaló que el texto francés de la decisión era auténtico, y afirmó explicitamente que la inminencia si es uno de los cuatro elementos de la definición establecida por las decisiones anteriores de la Corte y de la Comisión (58). Lo que es más importante, la decisión en el Caso de Grecia ofrece unas directrices bastante precisas con respecto a lo que se entiende por el término eminentemente relativo, "inminente". Afirmó que "la pregunta concreta formulada a la Comisión es si, el 21 de abril de 1967 (el día del golpe militar) existia una amenaza inminente, en el sentido de que se iba a realizar antes, o poco después de las elecciones en mayo, de inestabilidad y desorden politicos de tal magnitud que no se

(57) Ibid, pág. 97-8.

(58) Caso de Grecia, C.E.D.H, Fallo de la Comisión, párr. 153. 
iba a poder mantener la vida organizada de la comunidad" (59) (subrayado nuestro). Asi que, por lo menos en el sistema europeo por inminencia no se entiende ni una cuestión de dias - lo cual constituiria una amenaza actual - ni de meses - una amenaza potencial- sino más bien una cuest ón de semanas. En otras palabras, en el futuro inmediato previsible.

La Comisión también vindicó el punto de vista de los disidentes en el Caso Lawless al equiparar el concepto de un peligro excepcional con que "las medidas o restricciones normales permitidas por la Convención para el mantenimiento de la seguridad pública, la salud y el orden [sean] claramente inadecuadas" (60). Entre las múltiples implicaciones que puede tener tal interpretación, la más obvia es que no puede existir ningún peligro excepcional cuando, al servirnos de las palabras del Sr. Süsterhenn en el Caso Lawless, "la vida de todos los sectores -la política, la economia, e transporte, la educación y la prensa [y la administración de justicia] sigue igual que siempre" (61). La aplicación de este criterio en el Caso Lawless obviamente hubiera impedido el reconocimiento de una amenaza a la vida de la nación. Al aplicarlo a muchos paises de las Américas, dicha regla ciertamente conducirá de igual modo a la conclusión que no hay verdadera emergencia -o quizás a la conclusión de que las únicas alteraciones en el funcionamiento normal de la prensa, la educación, la administración de justicia y la politica, tienen su origen no en factores endajenos a la sociedad civil sino en el abuso por parte del gobierno de los poderes excepcionales. En otras palabras, que la única emergencia que afecta la vida de la nación es el estado de emergencia mismo.

A pesar de su simplicidad esta implicación del princip:o de que medidas normales han de ser netamente inadecuadas $-o$ sea que no puede existir ninguna emergencia cuando la vida sigue igual que siempre - es probablemente la aplicac'ón más importante del principio, y eso por dos razones. Primero, el criterio "la vida sigue igual" servirá para desenmascarar la ilegitimidad de los abusos más serios en el sentido de menos justificados del

(59) lbid, párr. 164.

(60) Ibid, párr. 153.

(61) Supra, pág. 34. 
derecho a la suspensión. Además es el criterio que con más facilidad se aplica, por lo tanto, el que más probablemente se aplicará, dada la circunspección con que actúan las autoridades internacionales cuando han de decidir si una supuesta amenaza a la vida de la nación es real o no. La Comisión Interamericana, aunque sin fundamentar su análisis en dicha jurisprudencia, efectivamente ha recurrido al concepto de que "la vida sigue igual", en sus informes sobre determinados paises.

El Grupo de Trabajo Ad Hoc y después el Relator Especial de la ONU sobre Chile también han aplicado el mismo criterio. aunque al igual que la Comisión Inter-Americana, lo hicieran sin reconocimiento explicativo de la jurisprudencia de los organos europeos de derechos humanos (62).

Ahora bien, es obvio que la decisión de la Comisión de que el principio de un peligro excepcional requiere la "clara insuficiencia de medidas y restricciones normales permitidas por la Convención para el mantenimiento de la seguridad pública, la salud y el orden" también tiene implicaiones que van más allá de la simple regla de que no existe ninguna emergencia cuando la vida sigue igual. A nivel de tipificación del derecho a suspender garantias, ello implica que la eficacia de las diferentes medidas represivas permitidas por los instrumentos internacionales en tiempos normales (las cuales bien pueden ser más amplias que las medidas y restricciones normalmente vigentes en una determinada sociedad), individual o colectivamente, constituyen un criterio para determinar si una determinada amenaza interna es de suficiente gravedad para legitimar la declaración de una emergencia pública. Esto obviamente requiere un análisis de la situación mucho más a fondo que la simple interrogación de si la vida sigue más o menos igual en aspectos especificos de la sociedad.

Eso a su vez implica, a nivel normativo. que un gobierno tiene una obligación en derecho internacional de determinar. antes de tomar cualquier medida que implica suspensión de normas sustantivas de derecho internacional, que las "medidas y restricciones" normalmente permitidas por el instrumento o ins-

(62) Véase pág. 57 a 59 , infra. 
trumentos en cuestión no serian adecuadas para proteger los intereses legitimos de la sociedad.

Por el momento, la aplicación estricta de esta regla ya sea en un sentido normativo o definitorio es poco probable a causa de la politica de realismo y discreción que prevale actualmente en los tribunales internacionales y que ha sido reconocida formalmente por la Comisión y la Corte Europea en la bien conocida doctrina de "margen de apreciación" (63). Esta negativa a evaluar con rigor la legitimidad del fundamento de un estado de emergencia también se manifiesta en el uso mismo del término "claramente inadecuado", asi como en la negativa de la Comisión en el caso del Norte de Irlanda de considerar la moderación o levantamiento gradual de medidas de emergencia como evidencia de que las medidas más estrictas originalmente empleadas fueron excesivas o innecesarias $a b$ inicio.

Existen razones válidas para esta politica de discreción, desde la presunción de que un gobierno nacional tiene más elementos que un tribunal internacional para evaluar el grado de peligro de una amenaza interna y la probable eficacia de respuestas alternativas a ella, al reconocimiento implícito de los verdaderos limites a la autoridad de órganos judiciales internacionales.

La aplicación de este principio en las Américas en el momento actual también sería obstaculizado por la falta de jurisprudencia existente sobre el alcance de las cláusulas de restricción, o el alcance de las restricciones a derechos permisibles en general, tanto bajo la Convención Americana como bajo el Pacto Internacional. Existe poca o ninguna jurisprudencia sobre dicha cuestión bajo la Convención Americana, y apenas se está comenzando a establecer jurisprudencia sobre el alcance de restricciones persimibles a los derechos bajo el Pacto Internacional. Asi cuentan con muy pocas directrices hoy en dia los Estados Americanos que parecen alteraciones internas y en consecuencia se ven obligados a decidir donde termina la facultad "normal" para restringir derechos en el interés de la seguridad nacional y

(63) Caso Lawless, (supra, nota 6), pág. 130. 131, Caso Lawless, (supra nota 38), pág. 
dónde comienza la suspensión de la misma obligación de respètar tales derechos, con todas las calificaciones, limites y restricciones que ellos comprenden.

Con el correr del tiempo, esta laguna en la jurisprudencia será progresivamente reducida por la actividad interpretativa de estos tribunales judic ales y quasi-judiciales que empezaron a funcionar recientemente. Mientras tanto, es útil recordar la observación de Kiss en el sentido de que, mientras "la clara intención es que las suspensiones son de carácter temporal, las limitaciones, en cambio, pueden ser permanentes" (64). De manera que si una determinada medida, permanentemente aplicada, no fuera consistente con los requisitos de una forma de sociedad democrática, se puede concluir que no cabe dentro del alcance de las cláusulas de restricción, sino más bien representa una suspensión de las normas que regulan la protección de los derechos humanos. Su legitimidad entonces, depende de si se cumplen los diferentes requisitos y limitaciones al derecho de la suspensión.

La decisión de la Comisión Europea en el Caso de Grecia' también ratificó la opinión del Sr. Süsterhenn en el Caso Lawless respecto a la importancia que tienen las intenciones de las fuerzas que supuestamente amenazan la vida de la nación. La evidencia indicó que los planes de contingencia de la oposición se centraban en tres posibles acontecimientos:

1) el uso de la fuerza o el fraude en las entonces inminentes elecciones por parte del partido conservador que estaba en el poder en ese momento,

2) la postergación indefinida de las elecciones por parte del mismo partido, o

3) la negativa de este partido de entregar el poder en caso de que perdiera dichas elecciones (65).

La Comisión observó que esto representaba:

(64) Kiss, A.C. "Permissible Limitations on Rigths", en The International Bill of Rights, supra, nota 71), pág. 290.

(65) Caso de Grecia, (supra, nota 58), párr. 159. 
"esencialmente un plan de acción política contra la derecha. Sus autores declaran que es su intención usar la fuerza sólo en la segunda y tercera situación... Nin guna de estas reacciones contempladas frente a las acciones de la derecha incluye el derrocamiento inminente del Gobierno legal por la fuerza" (66) (T.N.)

Puesto que la justificación ofrecida por el gobierno para la suspensión se fundaba en el alegado peligro de un arrebato inminente del poder del Estado, la decisión de la Comisión no enfatiza las dimensiones psico-sociales de la situación. Dice, sin embargo, lo siguiente:

"La Comisión, además, no acepta la sugerencia del Gom bierno demandado de que las manifestaciones callejeras, huelgas y paros en los primeros meses de 1967 alcanzaron la magnitud de una emergencia pública. Aunque, como en cualquier parte, las manifestaciones callejeras en Atenas y Salónica crearon ansiedad con respecto a personas y propiedad, las pruebas no demuestran que las fuerzas policiacas estuvieron en el limite, ni siquiera cerca de él. de su capacidad para controlar las manifestaciones y el desorden" (67) (T.N.)

La decisión asi ofrece por lo menos cierto apoyo a la tes's de que factores psicológicos son pertinentes, pero esencialmente de secundaria importancia y por lo tanto deben subordinarse a la evaluación de la amenaza material al orden público.

Como ya hemos visto, la protección otorgada por el Derecho Internacional contra los abusos del estado de excepción fue debilitada por la substitución del criterio textual de la Convención de una "amenaza a la vida de la nación" por la fórmula " $A M E$ NAZA A LA VIDA ORGANIZADA DE LA COMUNIDAD'. En el Caso de Grecia, sin discusión explícita de tal norma, la Comisión sustituyó a este por la fórmula "instabilidad y desorden de tal magnitud que impedia desarrollar la vida organizada de la comunidad" (68). El concepto de amenaza a la vida de la nación, como observó el Sr. Süsterhenn en el Caso Lawless, literal-

(66) Id.

(67) Ibid, párr. 160.

(68) Ibid, părr. 153. 
mente sugiere que la continuación de la existencia misma de la nación esté en peligro. Una amenaza a la vida organizada de la comunidad sin embargo, podria interpretarse en el sentido de significar no más que el peligro de cierto grado de obstrucción o interrupción de la vida organizada de la comunidad, con la única condición de que toda la población sea afectada de alguna manera.

Al interpretar esta norma a la luz de la situación fáctica descrita en Lawless, no puede sino concluirse que bastaria para la suspensión de garantías mucho menos que la interrupción total de esta "vida organizada", entendiendo por esta, por ejemplo, la serie de factores enumerados por el Sr. Süsterhenn, o sea, la política, la educación, el transporte, la prensa y la administración de justicia. El retorno al concepto de un peligro de que la vida organizada asi definida "no podría desarrollarse", el cual implica la verdadera paralización de las infraestructuras sociales, económicas y políticas de la nación o el colapso de la sociedad civil, representa entonces el retorno a un concepto más fiel al texto de los instrumentos internacionales. Un vistazo a la historia moderna de estados de excepción en América Latina, comenzando, por ejemplo hace 10 años con la disolución de la Asamblea Legislativa en Uruguay y el golpe en Chile en 1973, bastai ia para concluir que son pocos los estados de excepción que cumplen con tal requisito.

\subsection{El Caso de Irlanda del Norte}

En Inlanda us. el Reino Unido, la existencia de un estado de emergencia no estuvo en disputa. Irlanda, el Gobierno solicitante, reconoció la existencia de una emergencia del tipo requerido por Articulo 15 de la Convención, pero rehusó las medidas de emergencia aplicadas en Irlanda del Norte por ser incompatibles con otras tres normas redactadas en el mismo artículo: el requerimiento de "estricta necesidad", el carácter absoluto del derecho a la vida y la prohibición de la tortura, y el principio de la no-discriminación (69).

(69) C.E.D.H., serie A, 1978 (Irlanda vs. Reino Unido, Fallo de 18 enero de 1978, pág. 23). 
Aunque Irlanda no se refirió a este aspecto, la Comisión y después la Corte si examinaron motu propio la cuestión de si existia o no una emergencia que legitimara la suspensión. La situación imperante en Irlanda del Norte sin embargo, era tan grave que una consideración detallada de los diferentes elementos de la definición que se había establecido en los Casos Lawless y de Grecia no se consideró necesaria. En el periodo anterior a 1975 al cual la Comisión y la Corte se refirieron, la crisis habia resultado en la pérdida de 1.100 vidas, más de 11.500 lesionados, y en daños a la propiedad de un valor de 140 millones de libras esterlinas. En el año 1971, cuando se dio un aumento repentino de violencia en un sólo mes explotaron 94 bombas. En un pais cuya población era de solamente 1.5 millones, casi treinta personas fueron asesinadas por mes en la última parte de 1971 y en 1972. En sólo el mes de julio, 1972, se informaron de noventa $\mathrm{y}$ cinco asesinatos $\mathrm{y}$ de 2.800 tiroteos.

Estas y otras estadísticas formaron la base principal del reconocimiento por la Comisión de la existencia de una verdadera emergencia. Bajo el titulo "observaciones generales" la Corte declaró:

"Esta bien establecido que en todo el tiempo en discusión ha habido un problema de seguridad muy serio en Irlanda del Norte, como está indicado por la cifras... de muertes, explosiones, daños a personas y propiedad" (70) (T.N.)

$\mathrm{Su}$ conclusión legal, que no incluye ninguna referencia a la jurisprudencia existente en la materia, dice sencillamente:

"La Comisión considera que existió en Irlanda del Norte durante todo el periodo en cuestión en el caso actual, una emergencia pública que amenazaba la vida de la nación en términos del Artículo 15. El nivel de violencia. con explosiones, tiroteos, y motines, se produjo en una escala mucho más allá de lo que podría llamarse desórdenes civiles menores. Es evidente que en muchos casos la violencia usada estaba planeada con anticipación, por facciones de la comunidad organizadas y ac-

(70) Ibid, pág. 106 
tuando segứn métodos paramilitares. En gran parte la violencia fue dirigida contra las fuerzas de seguridad, las cuales fueron severamente obstaculizadas en su función de mantener o restaurar la paz pública. La existencia de una emergencia dentro del significado del Artículo 15 no está en disputa entre las partes. La Comisión decide, entonces, que las condiciones fácticas para la aplicación del Artículo 15 quedan cumplidas" (71) (T.N.)

Ciertamente es significativo que ante evidencias tan claras de una genuina emergencia, la Comisión estimó suficiente referirse a tales estadisticas. Igualmente significativo es el hecho que, aún con un nivel tan alto de violencia y la ausencia de duda alguna respecto a la existencia de una grave emergencia, la Comisión estimó imprescindible un examen cuidadoso para determinar si las medidas específicas de emergencia empleadas fueron "estrictamente requeridas por las exigencias de las circunstancias".

\subsection{El Sistema Americano}

Aunque el artículo sobre la suspensión de garantias en la Convención Amer:cana, es inspirado por el artículo correspondiente, de la Convención Europea, existen diferencias considerables en la definición de una emergencia que permita la suspensión. Mientras la Convención Europea hace mención a la guerra u "otra emergencia pública que amenaza la vida de la nación", la Americana hace referencia a "guerra, peligro público u otra emergencia que amenaza la independencia o seguridad de un Estado Parte".

Como ha observado Buergenthal, la primera impresion que uno tiene al comparar los dos textos es que, por no requerir que la emergencia sea de tal naturaleza como para constituir una amenaza a la vida misma de la nación podria interpretarse que la Convención Americana permite la suspensión en situaciones de peligro menor que las previstas por la Convención Europea o el Pacto Internacional (este último es idéntico al Europeo en este

(71) Ibid, pág. 117 . 
aspecto) (72) La comparación de la Convención Americana con la jurisprudencia existente del sistema Europeo relativo al significado de una amenaza a la vida de la nación sin embargo, sugiere que las diferencias no son tan grandes como pareceria mostrar una simple comparación de los textos de los dos artículos.

Los resúmenes de los debates de la Conferencia Especializada de 1969, en donde fue adoptada la Convención Americana, desafortunadamente no contienen ninguna explicación de las razones por las cuales se varió la fórmula usada en los otros instrumentos internacionales (73). Sin embargo, en el estudio de la Comisión Interamericana del ante-proyecto, se hace el comentario siguiente al respecto:

"Tengo entendido que esta expresión cubre exclusivamente las siguientes situaciones: un peligro real $e$ inminente a la existencia del pais como nación; a la sobrevivencia del Estado como entidad política soberana e independiente; a la integridad del territorio; al respecto por la constitución política vigente; al ejercicio de poderes legitimos por las autoridades constitucionales. También incluye la situación de peligro serio e inminente de alteración profunda de la paz social o del orden público de tal carácter que pone en peligro la seguridad "nterna del Estado" (74).

Esta interpretación parece referirse a tres categorias distintas de situaciones. Las tres primeras cláusulas, "peligro a la existencia del país como nación, a la sobrevivencia del Estado como entidad politica soberana $e$ independiente, y a la integridad del territorio", se refieren al peligro de guerra de conquista por un poder extranjero o guerras de secesión.

(72) Buergenthal, T. "Las Convenciones Europea y Americana: Algunas Similitudes y Diferencias" en La Convención Americana sobre Derechos Humancs, OEA Washington, 1980, pág. 190. Nota 26.

(73) Conferencia Especializada Interamericana sobre Derechos Humanos. San José, Costa Rica, 7-22 Noviembre 1969.

Actas y documentos, Doc. OEA/Ser. K/XVI/12, Washington 1978 (reprint), pág. 263-7.

(74) Citado en Norris (supra nota 3) pág. 193. 
En cuanto al respecto por la constitución, si se quiere evitar una interpretación tan amplia que incluya aún la mera crítica de ella, debe entenderse en el sentido de respeto en la práctica, no respeto en un plano más abstracto. Este segundo tipo de situación, entonces, comprende el peligro de un golpe de Estado o por lo menos una interferencia u obstaculización importante del funcionamiento de las instituciones estatales reconocidas por la Constitución.

La tercera categoria se define como el peligro de "alteración profunda de la paz social o del orden público de tal carácter que pone en peligro la seguridad interna del Estado". Ahora, el autor de este mismo documento, en su estudio preliminar sobre el tema, enfatizó que "cada gobierno democrático tiene poderes amplios para combatir amenazas [a] orden público] con medidas ordinarias. El poder policiaco, leyes sobre traición y sedición y el código penal, no dejan a los gobiernos impotentes". La Convención Americana, igual que el pacto Europeo y el Internacional, reconocen expresamente el derecho del Estado de restringir determinados derechos para poder proteger el orden público y la seguridad (75). Seria lógico, por lo tanto, equiparar esta tercera categoría a una alteración tan profunda que los métodos ordinarios disponibles para controlar tales alteraciones sean inadecuados.

Este, desde luego, es precisamente uno de los elementos de la definición de la "amenaza a la vida de la nación" desarrollada por los órganos competentes de la Convención Europea. En realidad esas tres categorias de situaciones de emergencia descritas en el trabajo preparatorio de la Comisión Interamericana sobre la cuestión de la suspensión son substancialmente compatibles por no decir idént cas, con el cotenido del concepto de una "amenaza a la vida de la nación" tal y como ha sido definido en el sistema europeo. La eventual adopción de interpretaciones armoniosas de los dos términos por parte de las instancias competentes seria de mucho provecho, puesto que casi todos los Estados Partes a la Convención Americana también han

(75) Véase en general el articulo de Kiss, A.C., "Permissible Limitations on Rights" en The International Bill of Rights (supra, nota 11), pág. 290. 
ratificado el Pacto Internacional en el cual figura la misma definición empleada por la Convención Europea (76).

Hasta ahora, la Comisión Interamericana no ha recurrido a los trabajos preparatorios ni a la jurisprudencia de ningún otro órgano internacional al interpretar el significado de la cláusula de "peligro público u otra emergencia". En realidad, son escasos los casos en que se puede decir que se interpreta o aun que se aplica tal norma.

El Informe Anual de la Comisión de 1981, por ejemplo, contiene un comentario relativamente detallado sobre la problemática de estados de emergencia (77). Lo sorprendente es que el comentario no contiene ninguna referencia expresa al Articulo 27 de la Convención Americana, y el análisis general desarrollado se refiere a estados de emergencia en nueve paises sin distinguir entre Estados Partes y Estados no Partes a la Convención.

Desde la entrada en vigencia de la Convención en 1978, la Comisión ha publicado estudios de la situación de los derechos humanos en los siguientes paises: Panamá y Haiti (1979), El

(76) Son Estados Partes o ambos Pactos los paises siguientes:

$\begin{array}{ll}\text { Bolivia } & \text { Nicaragua } \\ \text { Colombia } & \text { Panamá } \\ \text { Costa Rica } & \text { Perú } \\ \text { Ecuador } & \text { República Dominicana } \\ \text { El Salvador } & \text { Uruguay } \\ \text { México } & \text { Venezuela } \\ & \text { Jamaica }\end{array}$

Son Estados Partes únicamente al Pacto de San José:

Guatemala

Grenada

Haiti

Haiti

Son Estados Partes únicamente al Pacto Internacional sobre los Derechos Civiles y Politicos:

Chile

Suriname

Uruguay

S. Vicente y Las Granadinas

Guyana

Trinidad y Tobago

(77) Informe Anual de la C.I.D.H. 1980-1981, OEA, Washington 1981. pág. 114, (versión inglesa). 
Salvador (1980), y Bolivia, Colombia, Guatemala y Nicaragua (1981), (78). Con la sola excepción de Panamá, un estado de emergencia estuvo en vigencia en cada uno de estos paises por lo menos parte del tiempo abarcado por la investigación emprendida por la Comisión.

Tales informes, como ya se sabe, son básicamente descript vos, no analíticos. La práctica de usar éstos en negociaciones con los gobiernos con el fin de lograr avances concretos con respecto a problemas especificos conlleva sacrificios en cuanto al rigor juridico de ellos. Además, en razón de recursos limitados o bien por causa de una tradición derivada de la tenue base legal sobre la cual se fundamentaron las primeras investigaciones de la Comisión (o por una combinación de ambos factores) ésta ha tendido a enfocar sus actividades sobre el "núcleo esencial" de los derechos más fácilmente reconocidos como el legitimo objeto de la preocupación de la comunidad internacional y que son justamente los derechos cuya suspensión no se permite bajo ninguna circunstancia.

Asi, en situaciones referentes a estados de emergencia la Comisión ha enfocado la obligación de proteger los derechos que no admiten la suspensión, y pocas veces ha encarado la cuestión de la legitimidad de la emergencia como tal.

En sólo uno de los casos antes mencionados -el informe sobre Bolivia en 1981 - la Comisión decidió expresamente que la tipologia de emergencia prevista por el Artículo 27 no existia, $y$ aún en este caso los razonamientos que permitieron llegar a esta conclusión no fueron explicitados claramente. Con respecto al primer requisito del Pacto, la existencia de una amenaza a la independencia o seguridad del Estado, la Comisión se limitó a reiterar el texto del Artículo 27 para concluir que "en opinión de la Comisión, las autor:dades bolivianas excedieron los limites de la acción estatal al hacer caso omiso de las restricciones al uso de tales medidas estipuladas en la Convención Americana

(78) Resúmenes de cada uno de esos informes se encuentran en La Comision Interamericana de Derechos Humanos, Diez Años de Actividades, 19711981, OEA, Washington, 1982. 
con respecto a la gravedad y periodo de tiempo en que tales medidas deberian mantenerse en vigencia" (79). Aún en Haití, donde la justificación para la suspensión de garantias constitucionales es transparentemente inadecuada, - se suspenden por siete meses cada año cuando el Congreso no está en sesión- la Comisión no falló explicitamente sobre este punto $(80)$.

Por otra parte, aunque la Comis ón sostiene que es competente para investigar el cumplimiento por cualquier Estado $\mathrm{M}$ embro de la OEA de obligaciones contratadas en virtud de todo tratado referente a derechos humanos, sea regional o universal, no ha recurrido a las normas del Pacto internacional para determinar la legitimidad de estados de emergencia en paises donde éste, y no la Convención Americana, estaba en vigencia. Este fue el caso, por ejemf'o, en los numerosos informes sobre Chile y Uruguay publicado después de 1976 (81).

Para recapitular, hasta ahora en el sistema interamericeno no existe ninguna jurisprudencia digna del nombre. fundada en el derecho Internacional positivo, en cuanto al contenido preciso de una amenaza interna que justifique la suspensión de derechos humanos. Sin embargo, si existen no solamente argumentos juridicos válidos sino también fuertes razones para la armonización de sistemas juridicos internacionales que favorezcan una interpretación aparentemente más flexible de la definición contenida en el Artículo 27 (1) de la Convención Americana, de tal forma que resulte en un nivel de protección contra el recurso injustificable a medidas de emergencias no inferior al requerido por los otros instrumentos. Además, la experiencia de los uiltimos años ha resultado en un alto nivel de conciencia y preocupación en América respecto al abuso de estados de emercencia, lo que permite esperar que los órganos interamericanos de protección

(79) Informe sobre la Situación de los Derechos Humanos en Bolivia, OEA/ Serv. L/V/II. 53/Doc. 6, Rev. 2, Conclusión No 3.

(80) Informe sobre La Situación de los Derechos Humanos en Haiti, OEA/ Serv. L/V/II. 46, Doc. 66, rev. 1.

(81) Véase los Informes Anuales del C.I.D.H. de los años 1978-1979, 1980, 1981 y 1982, resumidos en la C.I.D.H., Diez Años de Actividades, (supra, nota 78). 
de los derechos humanos desarrollarán criterios legales super'ores a los que han sido reconocidos hasta ahora en el sistema de derechos humanos europeo para la determinación de la legitimidad de estados de emergencia.

\subsection{La Jurisprudencia del Comité de Derechos Humanos}

La jurisprudencia bajo el Pacto Internacional sobre Derechos Civiles y Políticos en cuanto a las circunstancias que satisfacen el criterio de una amenaza a la vida de la nación también es escasa, aunque no por las mismas razones que explican la falta de jurisprudencia en el sistema interamericano.

Como ya se sabe, el Comité de Derechos Humanos, órgano encargado de supervisar la implementación del Pacto por los Estados Partes, expresa su opinión sobre cuestiones relacionadas a la interpretación $y^{\prime}$ aplicación del Pacto de dos maneras: a través de los "comentarios generales" que formula cada año para la Asamblea General de la ONU y los Estados Partes, y a través de las opiniones adoptadas por el Comité al examinar casos individuales recibidos en conformidad con el Protocolo Facultativo del Pacto. Aunque se publican resúmenes bastante detallados del intercambio de puntos de vista entre el Comité y determinados Estados Partes, la práctica general del Comité es abstenerse en este contexto de formular opiniones concertadas sobre cuestiones substantivas referentes a la implementación del instrumento.

Hasta este momento, se ha emitido un sólo "comentario general" respecto al Articulo 4 del Pacto, el cual aporta poco nuevo acerca de las caracteristicas de una amenaza interna que justificaría la suspensión. "Medidas tomadas bajo el Articulo 4 son de carácter excepcional y temporal", afirma el Comité, "y sólo pueden durar mientras se amenace la vida de la nación" (82). Este énfasis sobre la naturaleza esencialmente transitoria de las emergencias es útil, sobre todo dado el grave proble-

(82) Informe del Comité de Derechos Humanos, UN Doc. A/36/40, New York, 1981, pág. 110 (versión inglesa). 
ma de la "institucionalización" de los estados de sitio que han vivido numerosos países latinoamericanos, pero la experiencia también demuestra muy claramente que existe una necesidad urgente de directrices más precisas y competentes sobre la gravedad o magnitud de situaciones que justifiquen la suspensión (83).

Las decisiones del Comité sobre casos individuales incluyen tres denuncias que surgieron bajo el ahora revocado estado de emergencia en Colombia y un número más grande que han resultado de la emergencia de larga duración todavia imperante en Uru,guay (84). Sin embargo, en ninguno de ellos ha tenido el Comité la oportunidad de determinar si la amenaza a la seguridad interna cumplió con los requisitos como para justificar la suspensión de sus obligaciones en materia de derechos humanos. El Gobierno de Uruguay nunca proporcionó la información necesaria para evaluar la legitimidad de la emergencia como justificación de sus acciones y en casos recientes aún parece haber dejado de invocar la emergencia como justificacción de sus acciones. El Gobierno de Colombia por su parte pretendió servirse del estado de emergencia entonces vigente para justificar transgresiones de derechos que si son clasificados como "suspendible". pero los cuales no figuraban en la anterior notificación de suspensión en la cual Colombia había pretendido que el estado de sitio sólo afectara la libertad de expresión y de reunión. Por esta razón, el Comité rehusó examinar en detalle la legitimidad del estado de emergencia, declarando que "simplemente invocar la existencia de un estado de emergencia" sin precisar oportunamente sus efectos no le permite a un estado "evadir obligaciones contraidas en virtud del Pacto" (85).

(83) Sobre el concepto de institucionalización, véase Coloquio sobre la Politica de Institucionalización del Estado de Excepción (Uruguay) SIJAU, Paris, 1981, y el "Etude Questiaux" (supra, nota 1) pág. 27 (versión francesa).

(84) Véase los Informes del Comité de Derechos Humanos de los años 1979 a 1982, comentado por el presente autor en la Revista de la Comisión Internacional de Juristas, Nos. 25 (Dic. 1980) y 28 (Junio 1982).

(85) Caso Salgar de Montejo, Comunicatión No R15/64. Informe del Comité, UN Doc. A/37/40, New York, 1982, pág. 181, párr. 103. 


\subsection{El Trabajo del Grupo Ad Hoc Sobre Chile}

Aunque la jurisprudencia del Comité todavía es bastante escasa, los criterios redactados en el Pacto también se han aplicado por otra autoridad del sistema de las Naciones Un das, el Grupo de trabajo Ad Hoc sobre Chile.

Constituido por un grupo de juristas eminentes procedentes de regiones geo-politicas y sistema legales diversos, y cuyos informes han sido recibidos favorablemente por la Asamblea General de la ONU, los pronuciamientos del Grupo aunque no esta facultado para interpretar la Convención, son de gran valor juridico.

El grupo comienza su análisis de la legitimidad del estado de excepción con una revisión de los argumentos presentados por ambos lados. Para sostener su posición, el gobierno hizo referencia al descubrimiento de armas escondidas y un hospital clandestino, la circulación de folletos subversivos, propaganda extranjera dirigida contra el gobierno y el hecho de que "personas buscaban contactos" con embajadas extranjeras. Por el otro lado, se argumentó que no existian, ni estaban en proceso de organizarse, fuerzas rebeldes o sediciosas organizadas, y que además hubiera sido imposible organizar tales fuerzas en las circunstancias que prevalecian al momento de la invest'gación o sea dieciocho meses después del golpe (86).

Una evaluación del fondo de dichos argumentos hubiera resultado en una contribución importante a la doctrina en materia de estados de excepción, pero el Gobierno rehusó permitir una investigación in situ, lo cual impidió una evaluación adecuada de la evidencia. En estas circunstancias el Grupo anunció sus conclusiones en los siguientes términos:

"No obstante repetidas indagaciones, el Grupo Ad Hoc de Trabajo no ha encontrado, hasta ahora, ningún elemento de valor que atestiguen la existencia de un

(86) Progress Report of the Ad Hoc working Group... on Chile, UN Doc. A/10285, 7 Oct., 1975 párr. 106. 
grado de alteración interna que pudiesen haber motivado la suspensión extensiva de garantias constitucionales que se produjo en Chile. El Gobierno no ha comprobado ninguna motivación objetiva para la existencia de una situación de emergencia en este momento..." (87) (traducción libre).

En su Séptimo Informe, somet:do en octubre de 1978 des pués de que finalmente se le permitió al Grupo efectuar una investigación in situ, otra vez se analizó a la legitimidad del estado de excepción. Al señalar que según las leyes chilenas un estado de emergencia se justifica únicamente por la existencia de una guerra, amenaza de invasión externa o ataque, o "desastre público", el Grupo afirmó que:

"Aunque el término 'desastre público' fuese interpretado incluyendo graves alteraciones sociales, el Grupo no ve ninguna razón para la declaración del estado de emergencia; $y$ al aferrase a esta posición el Grupo se basa no solamente en lo que observó directamente durante su visita, sino también en las declaraciones del gobierno chileno. El Sr. Sergio Fernández, Ministro del Interior, dijo en su discurso '... como todo chileno puede ver hoy dia, nuestro país disfruta de paz y orden, que garantizan la seguridad del individuo y su familia'. También, el preámbulo del decreto se refiere a la calma, paz y orden general de que ahora se disfruta en todo el pais, con el resultado de que el desorden interno ha terminado y ahora es posible levantar el estado de sitio y el toque de queda por todo el territorio chileno" (80).

Con respecto a la legitimidad del estado de emergencia en el Derecho Internacional, el informe concluye:

"el Grupo durante su visita (de quince dias) no presenció nada ni recibió ninguna información que contradijera el contenido de la declaración del Ministro del Interior del 19 de abril de 1978, en la cual describió la calma, paz y orden total que rige en Chile hoy dia. A la luz de sus propias observaciones, y a raiz de las

(87) Ibid, parr. 122.

(88) UN Doc. A/31/331, párr. 77. 
declaraciones del gobierno chileno, en opinión del Grupo no existia una situación en Chile de 'amenaza la vida de la nación', y de ese modo no puede sino concluir que los requerimientos del derecho internacional que permiten se impongan limitaciones a los derechos humanos no han sido satisfechos" (89).

En el informe posterior de 1980, el Relator Especial (quien reemplazó el Grupo de Trabajo) extrajo de los mismos hechos una conclusión aún mas precisa y pertinente. Subrayó:

"Según declaraciones hechas por el Ministro de Interior al Grupo de Trabajo Ad Hoc, el estado de emergencia ahora en vigencia en Chile es de carácter preventivo, lo que equivale decir que en este momento no existe ninguna situación de 'emergencia pública' que amenace 'la vida de la nación' del tipo mencionado en el Articulo 4 del Pacto Internacional sobre Derechos Civiles y $\mathrm{Po}_{\mathrm{o}}$. líticos" (90).

Esta declaración categórica de que estados de emergencia "preventivos" no se permiten por el Pacto es, por supuesto, una regla de valor transcendental para la evaluación de la leg timidad de estados de excepción en toda Latinoamérica.

\section{CAPITULO III}

\section{EL PRINCIPIO DE "ESTRICTA NECESIDAD"}

\subsection{Consideraciones Generales}

Al estudiar la relación entre los derechos humanos y los Estados de excepción, es útil distinguir entre tres categorias de derechos. El primero consiste en los derechos que estan poco re-

(89) Ibid, párr. 104.

(90) UIN Doc. A/35/522, pârr. 31. 
lacionados con el orden público y la seguridad nacional, y por lo tanto, raras veces son directamente afectados por estados de excepción. Esos derechos incluyen, por ejemplo, los llamados derechos de familia. Otro consiste en los derechos que quedan completamente protegidos por los instrumentos internacionales contra la suspensión. Asi ambos pactos disponen expresamente que no se pueden suspender bajo pretexto alguno el derecho a la vida, a la integridad física, a la personalidad legal, libertad de religión o la prohibición de esclavitud y de leyes penales ex posti facto. (A esta lista la Convención Americana agrega ciertos derechos que no estan muy vinculados a los estados de excepción, tal como los derechos familiares y el derecho a la nacionalidad). El tercer grupo consiste en derechos que si están relacionados con el orden público y la seguridad y los cuales sí quedan sujetos a la suspensión durante épocas de emergencia. Entre ellos quizá los más relevantes son los derechos a la libertad personal y al debido proceso y a la libertad de asociación y expresión.

En virtud de su función regulatoria, el principio que preferimos llamar "de estricta neceside!d" y que a veces suele ser denominado "de proporcionalidad"," por ser el criterio que permite hasta que punto el Estado puede intervenir en esta amplia área de los derechos que admiten la suspensión, es de transcendental importancia para la protección de los derechos de los individuos durante estados de excepción. En verdad, en un mundo más perfecto en que no se recurriera a emergencias ficticias y donde se respetaran las limitaciones absolutas que rodean el "núcleo esencial" de los derechos humanos, ésta sería la limitación más pertinente al derecho a la suspensión. Es, por lo tanto un triste comentario sobre el estado del mundo contemporáneo que este principio esté tan descuidado en la práctica. Existe en América Latina una tradición de implementar estados de emergencia por medio de un decreto que suspende todos los derechos fundamentales que el Derecho Internacional o constitucional no haya clasificado como absolutos (91). En vez de adoptar un

(91) Sirvanse comparar la notificación de suspensión hecha por los gobiernos de Nicaragua $y$ de Polonia en virtud del Articulo 4 (3) del Pacto Internacional, los cuales dicen is lo pertinente:

"The Government of Nicaragua notified the Secretary-General that it 
plan de acción o "paquete" de medidas excepcionales derivado de un análisis de las características especificas de una determinada amenaza a la nación, la práctica normal simplemente otorga al Poder Ejecutivo una discreción casi ilimitada para determinar la respuesta apropiada a la situación de emergencia. Tal práctica indudablemente refleja la influencia de la tradición romana de la dictadura legal (92). Sin embargo, esta práctica está en contradicción directa con la filosofía de los instrumentos modernos de Derecho Internacional, especialmente el principio de que las medidas de emergencia sólo son legítimas hasta el punto en que sean "estrictamente necesarias". Esta norma, desde luego, no pretende exigir que medidas excepcionales en general deban ser estrictamente necesarias; tal interpretación haria superflua esta cláusula, puesto que la necesidad de medidas de emergencia, como hemos visto, es parte del concepto de un peligro o amenaza excepcional a la nación. Se aplica más bien a cada una de las disposiciones excepcionales que el Estado adopte.

El uso en castellano de la palabra suspensión se presta a cierta confusión. Es de subrayar que los textos de los instrumentos internacionales no reconocen un derecho a la suspensión de los derechos individuales per se. Lo que se reconoce literalmente es el derecho a:

“... adoptar disposiciones que, en la medida estrictamente limitada a las exigencias de la situación, suspen-

had decided to extend the state of national emergency for a six months period starting 26 July 1982, and that, as a consequence, the application of the following provisions of the Covenant has been suspended throughout Nicaragua during the period concerned:

Articles 1 to $5 ; 8$, paragraph $3 ; 9 ; 10 ; 12$ to $14 ; 17 ; 19 ;$ to $22 ; 26$ and $27^{\prime \prime}$.

\section{(26 agosto de 1982)}

... in connection with the proclamation of martial law by the Council of State of the Polish People's Republic, as based on article 33, paragraph 2, of Poland's Constitution, there has been a temporaty derogation from or limitation of application of provisions of articles 9, 12 (paragraph 1 an 2), 14 (paragraph 5), 19 (paragraph 2), 14 (paragrapi 5), 19 (paragraph 2), 21 and 22 of the Covenant, to the extent strictly required by the exigencies of the situation".

(1 febrero de 1982

(UN Doc. CCPR/C/2/Add. 6).

(92) Estudio Preliminar del Estado de Sitio, (supra, nota 4), pág. 7. 
dan las obligaciones contraidas en virtud de este Pacto..." (subrayado nuestro).

El concepto de la suspensión en el Derecho Internacional es derivado esencialmente de la práctica inglesa, puesto que fue el Reino Unido quien presentó y patrocinó los artículos pertinentes tanto en el Pacto Internacional como en la Convención Europea, los cuales sirvieron a su vez como modelo para el Art culo 27 del Pacto de San José (93).

La práctica inglesa que hoy dia prevalece en muchas partes del mundo no se basa en la suspensión de derechos per se sino más bien en el otorgamiento al Poder Ejecutivo de determinados "Emergency Powers", tales como el poder de detención sin cargo. Las consecuencias legales de tal otorgamiento de poderes excepcionales generalmente son menos amplias que las que resultan de la suspensión de derechos.

Normalmente la discreción acordada al Poder Ejecutivo no rebasa el nivel operacional y la posibilidad de escoger entre una gama de medidas represivas bien definida, y limitadas. Además, el ejercicio de tales poderes excepcionales normalmente puede ser recusado por vires, o sea por haber sobrepasado el alcance de la ley que les crea.

Sin duda, este modo de abordar la problemática de los estados de excepción se debe en primer lugar al hecho de que en Inglaterra misma no hay una constitución escrita, y además porque la doctrina inglesa de poderes de emergencia resultó en gran parte de la experiencia colonial, en donde ningún instrumento de jerarquía constitucional tampoco protegía los derechos de los gobernados (94). Sin embargo, a pesar de sus orígenes nada brillantes fue esta la doctrina que más influyó en las normas inter-

(93) Vease Hartman (supra, nota 29) pág. 4-8; Actos y Documentos, (supra, nota 73) pág. 264 (palabras del delegado de Brasil, Sr. Dunshee de Abranches).

(94) La legislación sobre los estados de excepción de Irlanda, Israel, India, Sri Lanka, Pakistán. Malasia, Ghana, Africa del Sur y Zimbahwe, por ejemplo, tienen antecedentes directos en la legislación del poder colo nial inglès. 
nacionales ahora vigentes y que a fin de cuenta ofrece una mejor protección a los derechos del individuo que lo que resulta de la escuela continental que otorga más discreción al poder ejecutivo.

La diferenc'a entre los dos enfoques se manifiesta hasta en el plano lingüistico. El uso de la palabra suspensión en castellano es una traducción imperfecta de la palabra inglesa derogation, la que no significa "suspender" sino más bien tomar medidas o acciones que no son congruentes con una determinada norma sustantiva. La palabra francesa dérogation tiene el mismo significado que el inglés. La palabra en castellano no es incorrecta, pero quizás ha contribuido a perpetuar una tendencia (que por cierto también tiene raices en una larga tradición juridica propia de América Latina) de pensar en términos de la suspensión de los derechos del hombre per se en lugar de la "toma de medidas" que, siendo "mprescindibles para enfrentar una emergencia, son reconocidas como legitimas aunque pueden infringir hasta cierto punto los derechos reconocidos.

Sin embargo, es interesante hacer notar que mientras que el vocablo suspensión figura en los instrumentos auténticos en el idioma español (la Convención Americana y el Pacto Internacional), la traducción oficial de la Convención Europea, publicada en el Boletin de Jurisprudencia Constitucional de las Cortes de España, dice textualmente "tomar medidas que deroguen las obligaciones" (94) bis.

El principio de estricta necesidad está consagrado en términos substancialmente idénticos en los dos instrumentos básicos de derechos humanos que tienen vigencia en América Latina. La Convención Americana se distingue del Pacto Internacional en que especifica que las medidas de emergencia son legítimas "en la medida $y$ por el periodo de tiempo estrictamente limitado a las exigencias de la situación". Es de alguna utilidad la referencia explícita a la dimensión temporal de la necesidad, en vista de la tendencia bien demostrada de los gobiernos en Latinoamérica tanto como en otras partes del mundo de prolongar las medidas

(94) bis. Boldtin de Jurisprudencia Constitucional, No 1, Mayo 1981, Madrid, pág. 64. 
de emergencia ad infinitum, aunque su función no es más que la de subrayar una limitación ya implicita en el texto del Pacto Internacional.

En este respecto el texto de la Convención Europea es idéntico al del Pacto Internacional. La Comisión Europea, en los casos Lawless e Irlanda del Norte en particular, ha tenido una experiencia provechosa en el uso de este principio para proteger derechos que, si bien son "suspendibles", constituyen en las palabras de un miembro de la Comisión "la esencia misma del derecho" y "los más fundamentales de todos los derechos fundamentales, menos la vida misma" (95).

\subsection{Jurisprudencia Europea: El Caso Lawless}

En el caso Lawless se vieron en litigio dos de los derechos más frecuentemente afectados por estados de emergencia: la libertad personal y las garantias judiciales. La libertad personal fue atañido por la práctica de la detención preventiva, en el sentido de no vinculado por la investigación de cargos penales. En cuanto a las garantías judiciales, se les estimaban violadas porque 'el procedimiento que llevaba a la detención era de carácter no judicial y violador de la presunción de inocencia (96).

Varios miembros de la Comisión enfatizaron la importancia de un examen estricto de la legitimidad de estas medidas. En una opinión suscrita por cinco miembros más, el Sr. Sörenson sostuvo:

"La detención de una persona en circunstancias fuera de las previstas por el Art. 5. par. 1 [es decir, detención preventiva] es una medida muy grave y debe ser escudriñada rigurosamente por la Comisión. El mero hecho de que una persona se considera peligrosa para el orden público y la seguridad, no puede justificar una restricción de su libertad personal si no se le puede condenar, por contravenir las leyes del pais" (97).

(95) Caso Lawless, (supra, nota 6), 144 (Mr. Süsterhenn).

(96) Id.

(97) Ibid, pág. 130 . 
Otro miembro, el Sr. Erim, añadió que, "en general, la suspensión de [la libertad personal y el debido proceso] sólo se permite como último recurso después de haberse recurrido a medidas menos drásticas". En particular, calificó el derecho de toda persona privada de su libertad de ser llevado sin demora ante un oficial judicial como "uno de los más fundamentales de los derechos consagrados por la Convención" (98).

La Comisión resolvió que la legitimidad de estas "suspensiones" se determinará por medio del siguiente criterio: las medidas excepcionales empleadas serian legitimas si no hubiera otras medidas a la vez "menos gravosas" y susceptibles de haber desarmado eficazmente la amenaza que enfrentaba la nación (99). Esto implica una doble interrogante: primero, ¿podía demostrarse que las "medidas ordinarias" - forzosamente menos gravosas o inconvenientes que las que impliquen la suspensión- eran inefectivas? Segundo, iexistian otras medidas de suspensión, diferentes a las escogidas por el Estado Parte, que hubieran sido a la vez efectivas y menos represivas?

En el Caso Lawless, la Comisión falló que la ineficacia de medidas ordinarias "quedó establecida en razón de la imposibilidad de conseguir evidencias provenientes de testigos civiles para permitir el procesamiento de miembros del IRA" (100). Se desprende de tal razonamiento que los criterios que sirven para determinar la validez de las medidas adoptadas debian de aplicarse con referencia a una necesidad bien concreta y particular. Más tarde en el caso de Irlanda del Norte, la Comisión declaró más explicitamente que referencias generales a la violencia y subversión no son suficientes como base para la evaluación de la necesidad (o sea legitimidad) de las medidas especificas puestas en práctica (101).

Al decidir que las medidas ordinarias eran inadecuadas. la Comisión pasó a dos interrogantes: si otras medidas excepcionales -en particular el uso de los tribunales militares o especiales

(98) Ibid, păg. 154.

(99) Ibid, pãg. 131 (Mr. Sorensen).

(100) Id.

(101) Caso Irlanda del Norte, (supra, nota 69), pág. 119. 
reconocidos por la legisación irlandesa- hubieran sido eficaces, y si hubieran representado una mayor o menor negación de los derechos del individuo.

La Comisión opinó que los juicios en cortes militares reco, nocidos por el Derecho irlandés, al reunirse en secreto o al aplicar normas de prueba menos rigurosas e imponer sentencias severas, hubieran sin duda tenido consecuencias más serias para los derechos de los individuos que la detención sin condena. El Si: Sörensen declaró que:

"Otra medida posible y eficaz sería, sin duda, la creación de tribunales militares para juzgar tales causas ya que estos tribunales no serían limitados por las reglas ordinarias de las pruebas. Esta medida seria, sin embargo, particularmente criticable. Un juicio que nó respeta las garantias usuales que sirven para evitar la condena de personas inocentes, y que puede desembocar en la sanción más severa, o sea la pena de muerte, puede poner en peligro el derecho humano más elemental y preciado, el derecho a la vida y no debería ser aceptado como una medida aplicable en virtud de el Art. 15, mientras se disponga de cualquier medida menos opresiva. La detención sin juicio, aunque se equipara a la supresión temporal de la libertad personal, no tiene el carácter tan grave e irrevocable de una condena por un tribunal militar. En mi opinión, el Gobierno de Irlanda tuvo razón al abstenerse de recurr: $r$ al establecimiento de tribunales militares" (102).

Otra posibilidad reconocida en las leyes irlandesas era el proceso por delitos contra la seguridad en "Tribunales Penales Especiales", cuyos miembros serian nombrados por el Gob'erno gozando de notables poderes para determinar sus propios procedimientos y con competencia sobre cualquier causa que les fuese referida por el "Attorney General". Como lo señaló el Sr. Waldock, las consecuencias de un juicio en uno de estos Tribunales Penales Especiales serian mucho menos gravosas que un juicio tribunal militar:

"Las objeciones de principio que existen para el uso de cortes y tribunales militares no se aplican, a mi juicio. 
a los Tribunales Penales Especiales. Bajo los términos de la Parte $V$ del Acto, el Gobierno estaria capacitado para nombrar en estos Tribunales a jueces y abogados de gran experiencia y de reputación intachable como garantia del carácter judicial de los tribunales. Además, otras dos disposiciones de la parte $\mathrm{V}$ contribuyeron en gran medida a descartar algunas de la objeciones más serias que conlleva el uso de Tribunales Especiales para causas criminales. La primera es que las reglas de evidencia aplicables en el proceso de una persona acusada ante el Tribunal Penal Ordinario irlandes también se aplican en todo proceso ante los Tribunales Penales Especiales y que, conforme con las disposiciones del Acto, la práctica y el procedimiento de este Tribunal deben, en cuanto sea posible, aplicarse en los Tribunales Penales Especiales. La segunda disposic ón -y esto es muy importante_ es que una persona condenada por un Tribunal Penal Especial puede apelar al Tribunal de Apelación Criminal..." (103).

La pregunta más difícil era entonces si un juicio en los tribunales especiales hubiera sido una alternativa viable $y$ menos gravosa que la detención sin cargo. Por un lado, algunos miembros de la Comisión opinaron que no serian ef:caces tales tribunales especiales en vista del grado de apoyo pasivo que gozaba el IRA y la consecuente dificultad para conseguir testimonios de cargo contra sus efectivos. Por otro lado, lo cual es más relevante, la Comisión decid:ó que la detención preventiva sólo podia evaluarse tal y como fue practicada. La realidad es que en Irlanda la detención preventiva estaba rodeada por garantias importantes, incluso el derecho a la apelación a una instancia especial compuesta de dos magistrados civiles y un oficial militar con formación en derecho, la revisión periódica por la legislatura nacional del número de personas detenidas y de sus datos personales y un cierto derecho a la revisión. Además, un factor al que la Comisión prestó mucha importancia fue la política del gobierno de excarcelar a cualquier persona que hiciera una declaración formal de su voluntad de respetar la ley. En estas circunstancias, tomando en consideración el margen de apreciación del gobierno, la Comisión concluyó "que no se podía decir que

(103) Ibid, pág. 120. 
la detención preventiva tenia consecuencias más serias que el enjuiciamiento en tribunales especiales" (104).

La Corte Europea de Derechos Humanos, al confirmar la decisión, subrayó la importancia de las cuatro garantias mencionadas, que fueron calificadas por un miembro de la Comisón como "la diferencia entre la detención como se practica por naciones que respetan la libertad y la detención practicada per d'ctaduras" (105).

Otro factor de peso indudablemente fue el hecho de que la detención no duraba más que unos cuantos meses. Si hubiera sido prolongada durante años. tal como ocurre en algunos paises de América Latina, esos órganos seguramente habrian llegado a la misma conclusión formulada por la Comisión Interamericana de Derechos Humanos en más de una oportunidad o sea, que la detención por periodos tan prolongados es una forma disfrazada de pena sin ni siquiera la pretensión de cumplir con el debido proceso, y obviamente más gravoso que el juicio en cortes especiales (106).

\subsection{Los Casos de Irlanda del Norte y de Grecia}

El caso de Irlanda del Norte en cierto sentido es parecido al caso Lawless. En cuanto a los derechos "suspendibles" (también se alegaron torturas y atentados contra el derecho a la vida). el principal tema en litigio era el uso de la detención preventiva y la amenaza a la vida de la nación, proveniente otra vez, de la misma organización paramilitar, el IRA. Ahora bien, a diferencia de la situación en Irlanda al final de la década de 1950. a fines de la década de 1960 y principios de la de 1970 Irlanda del Norte se habia convertido en el blanco de una feroz campaña de violencia con miras a derrocar al gobierno cuya intensidad excedió el nivel de violencia vivido por cualquier nación surame-

(104) Ibid, pág. 129-30 (Mr. Waldock) 132-3 (Mr. Sörensen, Berg, Petren, Crosbie and Skarphedinnson).

(105) Ibid, pág. 134 (Mr. Faber).

(106) Véase por ej. Informe sobre Argentina, Doc. OEA/Ser. L/V/II. 49/doc. 22, Washington. 1980, Conclusiones, párr. 1 (b). 
ricana durante esas décadas, con la posible excepción de los recientes sucesos en Perú (107).

Aún en una situación tan grave, sin embargo, la Comisión insistió en la diferencia entre la necesidad de un estado de excepción como tal y la necesidad de medidas concretas empleadas, así como la necesidad de pesar cada uno de esos elementos independientemente. Hizo hincapié en que "la justificación en términos del Artículo 15 no resulta automáticamente de un alto nivel de violencia. Debe existir un vínculo entre las caracteristicas de la violencia por un lado, y las medidas escogidas por el otro" (108).

La relación imprescindible entre las caracteristicas especifi. cas de la situación y las medidas empleadas en respuesta a aquellas fue definida en los siguientes términos: primero, tales métodos deben ser "aptos para contribuir" a la solución de un problema concreto que surge de la situación de emergencia, y segundo, que este problema "no pudiera solucionarse si sólo se recurriera a los procedimientos legales normales" (109). En este caso, la detención bajo poderes excepcionales fue considerada como "apta para contribuir al propósito de encontrar a individuos empeñados en organ:zar acciones terroristas o de participar en ellas", lo cual no podía, según dijo, lograrse por medio de procedimientos represivos ordinarios $(110)$.

La segunda cuestión considerada por la Comisión fue si las medidas excepcionales usadas en Irlanda del Norte, justificadas en términos del primer criterio o sea su vinculación con un problema concreto, se empleaban en forma excesiva, o, al contrario, con toda moderación posible y respeto a los derechos de los interesados. Asi la Comisión brindó una contribución de singular importancia a la jurisprudencia al declarar que, aun cuando se establece la necesidad de determinadas medidas de excepción:

(107) Supra, pág. 45.

(108) Caso Irlanda del Norte, (supra. Nota 69), pág. 119.

(109) Ibid, pág. 121.

(110) Id. 
"Las obligaciones contraidas en virtud de la Convención no desaparecen completamente. Sólo pueden ser suspendidas o modificadas hasta el punto estrictamente necesario... En las circunstancias, esta limitación puede requerir garantías contra el posible abuso, o uso excesivo, de medidas de emergencia" (111).

Reiteró que, "la suspensión de garantías normales podría llegar a ser excesiva si ninguna otra garantia tomara su lugar" (112). La Comisión notó que en Irlanda del Norte la detención fue protegida por garantías adicionales, judiciales o cuasi-judiciales, como el derecho de apelación a instancias especiales semejantes a las normalmente requeridas por las disposiciones de la Convención Europea en materia de garantias judiciales. Con base en esas garantias $y$, en general, del esfuerzo permanente del gobierno para afinar las medidas de emergencia e introducir garantias más completas, la Comisión decidió que la detención tal como se practicaba, no podia ser calificada de abusiva (113).

Al Contrario de lo ocurrido en el caso Lawless, no se hizo ninguna comparación entre los métodos empleados por el gobierno y otras alternativas que también hubieran implicado la suspensión de normas internacionales. La Comisión se limitó a cuestionar (1) la "relación" (link) entre las medidas actualmente empleadas y las características de la stuación de emergencia, y (2) la forma en que fueron aplicadas las medidas excepcionales escogidas, en particular los esfuerzos realizados para desarrollar nuevas garantias o mecanismos diseñados con el fin de limitar su abuso.

En el Caso de Grecia, no se abarcó la cuestión de estricta necesidad, pues la Comisión decidió de antemano que no existia ninguna emergencia de naturaleza tal que justificara la suspensión de la Convención (114). Sin embargo, externó su opinión de que la detención administrativa de "personas consideradas

(111) Ibid, pág. 119.

(112) Ibid, pág. 124 .

(113) Ibid, pág. 125-6.

(114) Supra, pág. 37-8. 
peligrosas al orden público y seguridad", tal como se practicó por el régimen militar griego, no hubiera cumplido con esta norma. aún en la hipótesis de que hubiera existido tal emergencia.

La decisión de a Comisión, con dos elementos de la situación que la Comisión estimaba conveniente nombrar en apoyo de su análisis, fue expuesta en estos términos:

"(1) Aunque las dos terceras partes de las personas detenidas bajo orden administrativo poco después del 21 de abril de 1967 han sido puestas en libertad y se les otorgó la amnistia a muchos de los presos condenados la policía de seguridad sigue deteniendo individuos de vez en cuando.

(2) Se ha vuelto a aplicar revisión por la Corte de Apelación de las condenas impuestas por el Consejo de Guerra, pero solo por delitos que no afectan la seguridad nacional o el orden público.

En tales circunstancias, cuando la policia de seguridad y los tribunales pueden desempeñar las funciones que les corresponden sin dificultad ni interferencia, la Comisión no puede fallar que la privación de libertad sin respeto por las condiciones que figuran en el Articulo 5 de la Convención, sea estrictamente necesaria conforme a las exigencias de la situación, aún admitiendo la hipótesis de que haya existido una emergencia pública que amenaza la vida de la nación griega desde abril 21, 1967" (115).

Lo más pertinente de este comentario de la Comisión es el concepto de que el tipo de contradicciones identificadas en el segundo punto pueden servir para desmentir la necesidad de una determinada medida de emergencia. Si bien no se puede pasar por encima la advertencia de la Comisión en el caso Irlanda del Norte de que los esfuerzos de buena fe para "suavizar" las medidas de emergencia no pueden interpretarse como prueba de que las medidas originalmente aplicadas eran excesivas, el considerar las incongruencias o contradicciones que demuestran la aplicación desigual de normas de emergencia como una prueba

(115) Caso de Grecia, (supra, nota 58), párr. 287. 
de la ilegitimidad de la aplicación de poderes de excepción es una contribución doctrinal de gran importancia en América, precisamente porque tales discrepancias y contradicciones suelen surgir cuando se proclaman estados de excepción con fines ocultos o políticos más bien que para responder a una verdadera ame. naza a la vida de la nación.

\subsection{La Jurisprudencia del Comité de Derechos Humanos}

Aunque el Comité de Derechos Humanos en numerosos casos ha encontrado violaciones de esta categoria de derechos "suspendibles", en muy pocos de ellos se ha presentado la oportunidad de aplicar la regla de "estricta necesidad". La razón principal para ello es que los gobiernos en cuestión no han proporcionado la información imprescindible para la aplicación de tal regla. En el caso de Uruguay, en particular, el Comité ha constatado violaciones del derecho a la libertad personal, de la dignidad humana, de la libertad de movimiento, de expresión y asociación, y de casi todas las garantias judiciales consagradas en el Pacto. Pero, en ninguno de estos casos ofreció el gobierno pruebas y ni siquiera argumentos fundados, en cuanto a la posible justificación de tales medidas (116).

En un caso, sin embargo, la Comisión (por lo visto motivado por el precedente establecido por la Comisión Europea en el caso de Grecia) consideró apropiado declarar que la medida empleada era tan excesiva que no podría considerarse just:ficada en situación hipotética alguna. La cuestión concreta era similar a la del caso DeBecker, es decir, se trataba de la suspensión de derechos civiles o políticos que en principio admiten la suspensión, pero por periodos de tiempo fijos que, de hecho o por presunción, exceden la duración de la emergencia misma.

En conformidad con el Protocolo Facultativo del Pacto Internacional, fue sometida una comunicación al Comité de Derechos Humanos por cinco personas que habian sido candidatos a diversos cargos públicos en las elecciones de 1966 y 1971 en

(116) Véase nota 84 , supra. 
Uruguay. Se quejaron de que el "Decreto Institucional № 4" les negó el derecho de participar en la actividad politica por un período de 15 años por la sola razón de haber sido ellos candidatos en las elecciones antes mencionadas.

El Comité falló que la medida era evidentemente excesiva, con base en el siguiente análisis:

\begin{abstract}
"8.4 Además, aún suponiendo que existiera una situación excepcional en el Uruguay, el Comité de Derechos Humanos no puede comprender qué razones podrian aducirse en apoyo del argumento de que, a fin de restablecer la paz y el orden público, es necesario privar a todos los ciudadanos que fueron candidatos de grupos marxistas en las elecciones celebradas en 1966 y 1971 de todos sus derechos politicos durantes un periodo de 15 años. Esta medida se aplica a todos indiscriminadamente, sin tomar en cuenta si esas personas trataron de difundir sus opiniones politicas por medios pacíficos, haciendo una apología de la violencia o recurriendo directamente a ella. El Gobierno del Uruguay no ha podido demostrar que sea necesario silenciar a todos los disidentes políticos para resolver una presunta situación de emergencia y allanar el camino hacia la libertad politica.
\end{abstract}

9. El Comité de Derechos Humanos, actuando de conformidad con el párrafo 4 del artículo 5 del Protocolo Facultativo, considera que, al prohibir a los autores de la comunicación la participación en toda actividad política durante un periodo de 15 años, el Estado Parte ha limitado injustificadamente los derechos que les garantiza el artículo 25 del Pacto" (117).

Ha reiterado su posción en una serie de casos y en el más reciente declaró "la opinión ponderada del Comité ha sido que el decreto por el que se priva de todos sus derechos humanos a todos los ciudadanos que, en su carácter de miembros de determinados grupos políticos, hayan sido candidatos en las eleccio-

(117) Informe del Comité UN Doc. A/36/40, New York, 1981. Caso Landineeli, Comunicación No R. 8134 . 
nes de 1966 y 1971 constituye una restricción indebida de los derechos politicos protegidos por el Artículo 25 del Pacto" (118).

Esta jurisprudencia es particulamente relevante en América Latina, sobre todo en paises como Chile, Uruguay y Surinam que son Estados Partes del Pacto Internacional, pero no de la Convención Americana, la cual da a los derechos politicos una mayor jerarquía y no admite la suspensión bajo ninguna circunstancia.

\subsection{La Comisión Interamericana}

Son escasas las declaraciones de la Comisión Interamer:cana sobre la norma de estricta necesidad, dadas las prioridades $y$ metodología que caracterizan la promoción de la observación de los derechos humanos. En su informe Anual 1979-1980, sin embargo, la Comisión emitió la siguiente recomendación respecto al efecto del estado de excepción sobre derechos "suspendibles" en Uruguay:

"Modificar o derogar la legislación de excepción que, como se ha señalado en este informe, en no pocos aspectos importa una seria limitación de los derechos humanos en Uruguay y que, en algunos casos, ha dado lugar a abusos manifiestos como, por ejemplo, las limitaciones a los derechos de asociación y reunión, a la cancelación por motivos políticos de los derechos jubilatorios y a la negativa para expedir pasaportes a ciertos uruguayos" (119).

Desafortunadamente, dada la importancia que revisten estas cuestiones en todo el continente, la Comisión no identificó los factores que la condujeron a concluir que estas restricciones en el goce de derechos "suspendibles" tales como la libertad de asociación y reunión eran excesivas.

(118) Informe del Comité, UN Doc. A/37/40, New York 1982. Caso Altesor, Comunicación No R. 2/10, párr. 14 .

(119) Doc. OEA/Serv. L/V/II. 50, pág. 125. 
En las conclusiones de su informe sobre Colombia en 1981 . la Comisión también critica un decreto de emergencia, ahora derogado, similar al "Acto Institucional" uruguayo condenado en la antes mencionada decisión del Comité de Derechos Humanos.

Afirmó:

"Si bien el Estatuto de Seguridad tiene carácter de excepción, otorga a las autoridades militares y policiales la facultad de imponer sanciones, permite el juzgamiento de civiles por tribunales militares $e$ incluye la tipif:cación de penas prolongadas incompatibles con la naturaleza excepcional que acredita" (120).

Es de suponer que la objeción a la imposición de penas lar. gas durante situaciones de energencia, las cuales en principio son de breve duración por su naturaleza misma, se basa en las mismas inquietudes que motivaron al Comité a rechazar la imposición de largas inhablitaciones políticas (aunque esta última medida también entraña los defectos adicionales de ser completamente no-judicial y de constituir a la vez una pena sin delito y una discriminación política). De la declaración algo eliptica de la Comisión no se puede deducir si lo censurable es la imposición de penas prolongadas por tribunales en las cuales las garantias normales no se respetan, o si (y si asi es, las razones precisas) al enjuiciar a civiles en tr bunales militares y el imponer restricciones a garantías judiciales por el derecho colombiano, también son por si incompatibles con el carácter excepcional del decreto. Esto también es lamentable, pues, la casi totalidad de los paises latinoamericanos actualmente bajo un rég:men de excepción se sirven de tribunales militares o especiales en los cuales las garantias ordinarias de un proceso justo no se apli can.

Esto nos lleva otra vez al problema espinoso que dividió la Comisión Europea en el caso Lawless; o sea, admitiendo la existencia de una emergencia que puede no ser controlada por medidas relativamente moderadas que no abarquen infracciones de las

(120) Doc. OEA/Ser. L/V/II. 53, dcc. 22 conclusiones pár. 3. 
garantias judiciales o la libertad personal (tales como la censura la prohibición de reuniones públicas e intensificación de registro). ¿Seria preferible detener sin enjuiciar, o enjuiciar en tribunales especiales que ofrecen menos protección contra una condena injusta? Existen argumentos de peso para sostener que nadie debería sufrir las consecuencias de medidas de emergencia después de terminada la emergencia, incluyendo los que cumplen condenas de prisión impuestas en juicios que carecian de garantias fundamentales. Por otro lado, a pesar de la casi universalmente aceptada doctrina, de que las emergencias son por naturaleza un fenómeno de corta duración, la realidad es que emergencia de 10 años o más no son escasas de tal modo que la Comisión Interamericana ha tenido que condenar la detención prolongada sin catgo como una forma de pena sin el debido proceso. Puesto que hay que presumir que solo las más ligeras penas privativas de libertad no exceden la duración de estados de excepción legitimos el cumplimiento estricto con normas internacionales significaria que no se permitiria ningún proceso por delitos sin el $p^{\top} e$ no respecto de las garantias judiciales esenciales, ni tampoco se permitiria por otra parte, que la detención preventiva exceda un periodo de tiempo estrictamente limitado.

Resulta, entonces, bastante dificil escoger entre abogar por el estricto cumplimiento de estas normas internacionales $\bar{y}$ un enfoque más realista, que reconoce que algún proceso es preferible a la detención prolongada sin ningún proceso y que en consecuencia se limita a mitigar los efectos de los procesos especiales. La Comisión Interamericana obviamente favorece la segunda alternativa $y^{r}$ ha puesto mucho énfasis en el uso de la amnistia, indulto $o$, por lo menos de la revisión de sentencias impuestas por tribunales especiales como método para limitar las consecuencias de las medidas de emergencia después del fin de la emergencia. Este enfoque, evidente por ejemplo en el informe de la Comisión sobre Nicaragua en 1981, hunde sus raices en una larga tradición latinoamericana de benevolencia hacia los vencidos en luchas internas, en aras de promover la reconciliación y la unidad nacional (121).

(121) Doc. OEA/Ser. L/V/II. 53, doc. 25 recomendaciones 3-5. 
El esfuerzo por mitigar las consecuencias de procesos especiales también implica minimizar las discrepancias entre las normas procesales aplicadas en aquellos y las normas vigentes en tiempos normales. Cuando se habla de derecho al "debido proceso", se refiere a una totalidad de más de veinte derechos concretos: el derecho a estar presente en el proceso, de ser asistido por un defensor de su elección, plena igualdad durante el proce so y muchos más. En un estudio publicado por la Com'sión Internacional de Juristas, el autor ha sostenido que es imposible, bajo ninguna circunstancia, justificar la suspensión de cualquiera de estos derechos con la posible excepción del derecho a un juficio público, a un juicio rápido y el derecho de interrogar a los testigos de cargo. Actualmente, sin embargo, la jurisprudencia de los órganos internacionales competentes incluye muy pocas directrices en cuanto a las circunstancias bajo las cuales se justificaria la suspensión de determinados derechos procesales. En esta materia, tal como en el área más extensa de los derechos "suspendibles" en general, como la libertad de asoc'arse y de expresión, es urgente, que tanto el Comité de Derechos Humanos como la Corte y la Comisión Interamericanas, procedan a definir con más claridad las limitaciones que se puedan desprender de los respectivos instrumentos internacionales para orientar y regular la acción de los Estados durante situaciones de excepción (122).

(122) States of Emergency: Their Impact on Human Rights, O'Donnell, ed., C.I.J. Ginebra, 1983, pág. 424-9. 